\title{
Synthesis and Antimicrobial Activity of Some New 3,5-Disubstituted Pyrazoles and Isoxazoles
}

Simha Pulla Reddy, Gudi Yamini, Donthamsetty V Sowmya, Venkatapuram Padmavathi and Adivireddy Padmaja*

Department of Chemistry, Sri Venkateswara University, Tirupati, Andhra Pradesh, India

\begin{abstract}
A new class of 3,5-disubstituted pyrazoles and isoxazoles were prepared from the Michael acceptors 1-furanyl / thiophenyl / pyridinyl-3-indole-prop-2-en-1-ones under ultrasonication and evaluated for antimicrobial activity. Amongst all the tested compounds fluoro substituted thiophene linked compounds $12 \mathrm{~b}$ and $18 \mathrm{~b}$ displayed promising antibacterial activity particularly against Bacillus subtilis and antifungal activity against Aspergillus niger. Furthermore, compounds with more number of electron withdrawing groups showed higher antimicrobial activity. This result indicates that compounds $12 \mathrm{~b}$ and $\mathbf{1 8 b}$ can be used as lead compounds in the future studies.
\end{abstract}

Keywords: Pyrazoles; Isoxazoles; Antimicrobial activity

\section{Introduction}

The five membered heterocyclic compounds with two heteroatoms particularly pyrazoles and isoxazoles have considerable interest in various fields because of their wide range of pharmacological and physical applications. A number of pyrazole and isoxazole derivatives possess antimicrobial [1-6], anti-inflammatory [7,8], anticancer $[9,10]$, analgesic $[11,12]$, anticonvulsant $[13,14]$, anthelmintic and antioxidant $[15,16]$ activities. Besides, pyrazole containing drugs celecoxib demonstrates anti-inflammation effect and inhibits COX2 [17] rimonabant functions as cannabinoid receptor and is utilized in obesity treatment [18] fomepizole inhibits alcohol dehydrogenase and sildenafil inhibits phosphodiesterase [19]. Isoxazole motif is ubiquitous in many natural products such as ibotenic acid, muscimol, isoxazole-4-carboxylic acid and drugs like valdecoxib, leflunomide, cloxacillin, oxacillin [20-24], dicloxacillin [25], isocarboxazide [26] and sulfisoxazole [27]. Among the various methods for the synthesis of pyrazoles, 1,3-dipolar cycloaddition and [2+3] cyclocondensation reactions are the prominent ones [28]. Among the different methods of isoxazole synthesis, [2+3] cycloaddition of 1,3-dipoles to alkynes and the reaction of hydroxylamine with 1,3-diketone or an $\alpha, \beta$-unsaturated ketones have gained importance [29]. Moreover, the activated olefins are valuable intermediates in a variety of synthetic transformations and useful as building blocks in the synthesis of carbocyclic and heterocyclic compounds. In fact, we have exploited various activated olefins to develop pyrazoles and isoxazoles and studied their biological properties [30-33]. Recently, ultrasound method has been successfully employed as non-conventional method, to promote 1,3-dipolar cycloadditions [34]. Hence, development of pharmacologically active heterocycles adopting simple and efficient methodologies is one of the major challenges for organic chemists. With this background and in continuation of our studies in this direction, the present work synthesis and antimicrobial activity of 3,5-disubstituted pyrazoles and isoxazoles under ultrasonication has been taken up.

\section{Experimental Protocols}

All the chemicals were purchased from commercial sources and used without further purification. Melting points were determined in open capillaries on a Mel-Temp apparatus and are uncorrected. The homogeneity of the compounds was checked by TLC (silica gel $\mathrm{H}$, $\mathrm{BDH}$, hexane/ethyl acetate, 3:1). The IR spectra were recorded on a Thermo Nicolet IR 200 FT-IR spectrometer as $\mathrm{KBr}$ pellets and the wave numbers were given in $\mathrm{cm}^{-1}$. The ${ }^{1} \mathrm{H}$ NMR spectra were recorded in $\mathrm{CDCl}_{3} / \mathrm{DMSO}-\mathrm{d}_{6}$ on a Jeol JNM $\lambda-400 \mathrm{MHz}$ spectrometer. The ${ }^{13} \mathrm{C} \mathrm{NMR}$ spectra were recorded in $\mathrm{CDCl}_{3} / \mathrm{DMSO}-\mathrm{d}_{6}$ on a Jeol JNM spectrometer operating at $\lambda-100 \mathrm{MHz}$. High-resolution mass spectra were recorded on Micromass Q-TOF micromass spectrometer using electrospray ionization. All chemical shifts were reported in $\delta$ (ppm) using TMS as an internal standard. The microanalyses were performed on a PerkinElmer $240 \mathrm{C}$ elemental analyzer. The temperature was measured by flexible probe throughout the reaction. Ultrasonication was performed in a Bandelin Sonorex RK 102H ultrasonic bath operating at frequency of $35 \mathrm{KHz}$.

General procedure for the synthesis of $(E)-1-($ furan-2-yl)-3- $(1 \mathrm{H}-$ indol-3-yl)prop-2-en-1-one (5a, b) / (E)-1-(5-bromothiophen-2-yl)3-(1H-indol-3-yl)prop-2-en-1-one (6a, b) / (E)-3-(1H-indol-3-yl)-1(pyridin-4-yl)prop-2-en-1-one (7a, b)

To a solution of substituted indole-3-carboxaldehyde (1) (1.0 $\mathrm{mmol})$ in anhydrous methanol $(4 \mathrm{~mL}), 2$-acetyl furan (2) / 2-acetyl5-bromothiophene (3)/4-acetyl pyridine (4) $(1.0 \mathrm{mmol})$ were added followed by diisopropylethylamine (DIPEA) $(0.33 \mathrm{mmol})$ and subjected to ultrasonication at a frequency of $35 \mathrm{KHz}$ at room temperature for 60 $80 \mathrm{~min}$. After completion of reaction (monitored by TLC), the contents of the flask were allowed to cool and poured into ice water. It was neutralized with $10 \%$ acetic acid. The separated solid was filtered, dried and recrystallized from 2-propanol.

(E)-1-(Furan-2-yl)-3-(1H-indol-3-yl)prop-2-en-1-one (5a): M.p. 190-191 ${ }^{\circ} \mathrm{C}$, yield 87\%; IR (KBr) $\left(\mathrm{cm}^{-1}\right): 3329(\mathrm{NH}), 1683(\mathrm{C}=\mathrm{O}), 1632$ $(\mathrm{C}=\mathrm{C}) ; 1 \mathrm{H}$ NMR $\left(400 \mathrm{MHz}, \mathrm{DMSO}-\mathrm{d}_{6}\right): \delta 6.93(\mathrm{~d}, 1 \mathrm{H}, \mathrm{HB}, \mathrm{J}=15.4 \mathrm{~Hz})$, 7.54-7.90 (m, 8H, Ar-H) $8.02(\mathrm{~d}, 1 \mathrm{H}, \mathrm{HA}, \mathrm{J}=15.4 \mathrm{~Hz}), 11.74(\mathrm{~s}, 1 \mathrm{H}$, NH) ppm; 13C NMR (100 MHz, DMSO-d $): \delta 133.9$ (C-HB), 137.1 (C-HA), $176.4(\mathrm{C}=\mathrm{O}), 111.3,112.9,113.1,113.8,115.3,118.6,120.8$, $125.2,125.6,134.4,147.8,152.4 \mathrm{ppm}$ (aromatic carbons). HRMS (m/z): $260.0687[\mathrm{M}+\mathrm{Na}]$; Anal. calcd. for $\mathrm{C}_{15} \mathrm{H}_{11} \mathrm{NO}_{2}: \mathrm{C}, 75.94 ; \mathrm{H}, 4.67 ; \mathrm{N}$, $5.90 \%$. Found: C, $76.05 ; \mathrm{H}, 4.70 ; \mathrm{N}, 6.02 \%$.

*Corresponding authors: Adivireddy Padmaja, Department of Chemistry, Sri Venkateswara University, Tirupati-517 502, Andhra Pradesh, India, Tel: +919440350194; E-mail: adivireddyp@yahoo.co.in

Received December 01, 2017; Accepted December 04, 2017; Published December 11, 2017

Citation: Reddy SP, Yamini G, Sowmya DV, Padmavathi V, Padmaja A (2017) Synthesis and Antimicrobial Activity of Some New 3,5-Disubstituted Pyrazoles and Isoxazoles. Med Chem (Los Angeles) 7: 371-380. doi: 10.4172/2161-0444.1000483

Copyright: $\odot 2017$ Reddy SP, et al. This is an open-access article distributed under the terms of the Creative Commons Attribution License, which permits unrestricted use, distribution, and reproduction in any medium, provided the original author and source are credited. 
(E)-3-(5-Fluoro-1H-indol-3-yl)-1-(furan-2-yl)prop-2-en-1-one (5b): M.p. $163-165^{\circ} \mathrm{C}$, yield 89\%; IR $(\mathrm{KBr})\left(\mathrm{cm}^{-1}\right): 3322(\mathrm{NH}), 1675$ $(\mathrm{C}=\mathrm{O}), 1634(\mathrm{C}=\mathrm{C})$; $1 \mathrm{H}$ NMR $\left(400 \mathrm{MHz}, \mathrm{DMSO}-\mathrm{d}_{6}\right): \delta 6.76(\mathrm{~d}, 1 \mathrm{H}$, $\mathrm{HB}, \mathrm{J}=15.2 \mathrm{~Hz}$ ), 7.63-7.65 (m, 7H, Ar-H) 8.13 (d, 1H, HA, J=15.2 Hz), $11.98(\mathrm{~s}, 1 \mathrm{H}, \mathrm{NH}) \mathrm{ppm}$; 13C NMR (100 MHz, DMSO-d $)$ ) $\delta 134.0(\mathrm{C}-$ HB), 137.5 (C-HA), $176.9(\mathrm{C}=\mathrm{O}), 110.6,112.7,113.5,113.4,115.4$, $117.7,125.3,125.4,134.6,147.3,153.3,157.0 \mathrm{ppm}$ (aromatic carbons). HRMS (m/z): $278.0593[\mathrm{M}+\mathrm{Na}]$; Anal. calcd. for $\mathrm{C}_{15} \mathrm{H}_{10} \mathrm{FNO}_{2}: \mathrm{C}, 70.58$; H, 3.95; N, 5.49\%. Found: C, 70.66; H, 3.97; N, 5.64\%.

(E)-1-(5-Bromothiophen-2-yl)-3-(1H-indol-3-yl)prop-2-en1-one (6a): M.p. 202-204 ${ }^{\circ} \mathrm{C}$, yield 90\%; IR $(\mathrm{KBr})\left(\mathrm{cm}^{-1}\right): 3326(\mathrm{NH})$, $1672(\mathrm{C}=\mathrm{O}), 1628(\mathrm{C}=\mathrm{C}) ; 1 \mathrm{H}$ NMR $(400 \mathrm{MHz}, \mathrm{DMSO}-\mathrm{d} 6): \delta 7.21(\mathrm{~d}$, $1 \mathrm{H}, \mathrm{HB}, \mathrm{J}=15.6 \mathrm{~Hz}), 7.65-7.88(\mathrm{~m}, 7 \mathrm{H}, \mathrm{Ar}-\mathrm{H}) 8.15$ (d, 1H, HA, J=15.6 $\mathrm{Hz}), 11.94(\mathrm{~s}, 1 \mathrm{H}, \mathrm{NH}) \mathrm{ppm} ; 13 \mathrm{C}$ NMR $\left(100 \mathrm{MHz}, \mathrm{DMSO}-\mathrm{d}_{6}\right): \delta 125.0$ (C-HB), 138.8 (C-HA), $180.4(\mathrm{C}=\mathrm{O}), 112.4,112.6,113.8,120.6,121.2$, $122.6,122.7,132.2,132.6,133.8,137.5,148.1 \mathrm{ppm}$ (aromatic carbons). HRMS (m/z): $353.9569[\mathrm{M}+\mathrm{Na}]$; Anal. calcd. for $\mathrm{C}_{15} \mathrm{H}_{10}$ BrNOS: C, 54.23; H, 3.03; N, 4.22\%. Found: C, 54.33; H, 3.08; N, 4.39\%.

(E)-1-(5-Bromothiophen-2-yl)-3-(5-fluoro-1H-indol-3-yl)prop2-en-1-one (6b): M.p. $177-179^{\circ} \mathrm{C}$, yield 92\%; IR $(\mathrm{KBr})\left(\mathrm{cm}^{-1}\right): 3318$ $(\mathrm{NH}), 1676(\mathrm{C}=\mathrm{O}), 1631(\mathrm{C}=\mathrm{C})$; $1 \mathrm{H}$ NMR (400 MHz, DMSO-d $\mathrm{d}_{6}$ : $\delta 7.04(\mathrm{~d}, 1 \mathrm{H}, \mathrm{HB}, \mathrm{J}=15.8 \mathrm{~Hz}), 7.52-7.83(\mathrm{~m}, 6 \mathrm{H}, \mathrm{Ar}-\mathrm{H}) 8.02(\mathrm{~d}$, $1 \mathrm{H}, \mathrm{HA}, \mathrm{J}=15.8 \mathrm{~Hz}), 12.02(\mathrm{~s}, 1 \mathrm{H}, \mathrm{NH}) \mathrm{ppm} ; 13 \mathrm{C} \mathrm{NMR}(100 \mathrm{MHz}$, DMSO-d6): $\delta 126.3$ (C-HB), 138.4 (C-HA), 180.7 (C=O), 112.7, 113.3, $114.0,121.8,122.3,122.9,124.1,132.7,137.3,140.1,148.3,157.6 \mathrm{ppm}$ (aromatic carbons). HRMS (m/z): $371.9470[\mathrm{M}+\mathrm{Na}]$; Anal. calcd. for $\mathrm{C}_{15} \mathrm{H}_{9}$ BrFNOS: C, 51.45; H, 2.59; N, 4.00\%. Found: C, 51.57; H, 2.63; $\mathrm{N}, 4.16 \%$.

(E)-3-(1H-Indol-3-yl)-1-(pyridin-4-yl)prop-2-en-1-one (7a): M.p. $209-211^{\circ} \mathrm{C}$, yield $88 \%$; IR $(\mathrm{KBr})\left(\mathrm{cm}^{-1}\right): 3336(\mathrm{NH}), 1688(\mathrm{C}=\mathrm{O})$, $1638(\mathrm{C}=\mathrm{C}) ; 1 \mathrm{H}$ NMR $\left(400 \mathrm{MHz}, \mathrm{DMSO}_{-} \mathrm{d}_{6}\right): \delta 7.23(\mathrm{~d}, 1 \mathrm{H}, \mathrm{HB}, \mathrm{J}=15.9$ $\mathrm{Hz})$, 7.61-7.92 (m, 9H, Ar-H) $8.17(\mathrm{~d}, 1 \mathrm{H}, \mathrm{HA}, \mathrm{J}=15.9 \mathrm{~Hz}), 12.01(\mathrm{~s}, 1 \mathrm{H}$, NH) ppm; 13C NMR (100 MHz, DMSO-d $): \delta 137.6(\mathrm{C}-\mathrm{HB}), 144.2(\mathrm{C}-$ HA), $188.2(\mathrm{C}=\mathrm{O}), 110.2,112.5,112.8,114.6,120.6,121.4,122.9,125.0$, 134.5, 140.9, $151.6 \mathrm{ppm}$ (aromatic carbons). HRMS (m/z): 271.0847 $[\mathrm{M}+\mathrm{Na}]$; Anal. calcd. for $\mathrm{C}_{16} \mathrm{H}_{12} \mathrm{~N}_{2} \mathrm{O}: \mathrm{C}, 77.40 ; \mathrm{H}, 4.87 ; \mathrm{N}, 11.28 \%$. Found: C, 77.49; H, 4.89; N, 11.39\%.

(E)-3-(5-Fluoro-1H-indol-3-yl)-1-(pyridin-4-yl)prop-2-en1-one (7b): M.p. $186-188^{\circ} \mathrm{C}$, yield 91\%; IR $(\mathrm{KBr})\left(\mathrm{cm}^{-1}\right): 3330(\mathrm{NH})$, $1686(\mathrm{C}=\mathrm{O}), 1633(\mathrm{C}=\mathrm{C}) ; 1 \mathrm{H}$ NMR $\left(400 \mathrm{MHz}, \mathrm{DMSO}-\mathrm{d}_{6}\right): \delta 7.08(\mathrm{~d}$, $1 \mathrm{H}, \mathrm{HB}, \mathrm{J}=15.7 \mathrm{~Hz}), 7.59-7.86(\mathrm{~m}, 8 \mathrm{H}, \mathrm{Ar}-\mathrm{H}) 8.23$ (d, 1H, HA, J=15.7 $\mathrm{Hz}), 12.09$ (s, 1H, NH) ppm; 13C NMR (100 MHz, DMSO-d6): $\delta 134.1$ (C-HB), 144.5 (C-HA), $188.4(\mathrm{C}=\mathrm{O}), 110.8,112.9,114.5,114.8,121.5$, 125.4, 125.5, 135.8, 140.3, 150.6, $157.2 \mathrm{ppm}$ (aromatic carbons). HRMS $(\mathrm{m} / \mathrm{z}): 289.0753\left[\mathrm{M}+\mathrm{Na}\right.$ ]; Anal. calcd. for $\mathrm{C}_{16} \mathrm{H}_{11} \mathrm{FN}_{2} \mathrm{O}: \mathrm{C}, 72.17 ; \mathrm{H}$, 4.16 ; N, 10.52\%. Found: C, 72.30; H, 4.20; N, $10.66 \%$.

General procedure for the synthesis of 3-(furan-2-yl)-5- $(1 \mathrm{H}-$ indol-3-yl)-2-pyrazoline (8a, b) / 3-(5-bromothiophen-2-yl)5-(1H-indol-3-yl)-2-pyrazoline (9a, b) / 3-(pyridin-2-yl)-5(1H-indol-3-yl)-2-pyrazoline (10a, b)

A mixture of 5/6/7 (1 mmol), hydrazine hydrate $(1.5 \mathrm{mmol})$ and ethanol $(6 \mathrm{~mL})$ was subjected to ultrasonication at a frequency of 35 $\mathrm{KHz}$ at room temperature for $70-90 \mathrm{~min}$. After completion of the reaction (monitored by TLC), the contents of the flask were poured onto crushed ice. The separated residue was extracted with dichloromethane. The organic layer was washed with water, brine and dried (an. $\mathrm{Na}_{2} \mathrm{SO}_{4}$ ). The solvent was removed under vacuum. The resultant residue was purified by column chromatography (silica gel, 60-120 mesh) using hexane/ethyl acetate (4:1) as eluent.
3-(Furan-2-yl)-5-(1H-indol-3-yl)-2-pyrazoline (8a): M.p. 208$210^{\circ} \mathrm{C}$, yield 80\%; IR (KBr) (cm-1): $3338(\mathrm{NH}), 1640(\mathrm{C}=\mathrm{C}), 1578$ $(\mathrm{C}=\mathrm{N})$; $1 \mathrm{H}$ NMR $\left(400 \mathrm{MHz}, \mathrm{DMSO}-\mathrm{d}_{6}\right): \delta 3.24(\mathrm{dd}, 1 \mathrm{H}, \mathrm{HX}, \mathrm{JAX}=6.5$ $\mathrm{Hz}, \mathrm{JMX}=10.7 \mathrm{~Hz}$ ), 4.28 (dd, 1H, HM, JAM=12.5 Hz, JMX=10.9 Hz), $4.43(\mathrm{dd}, 1 \mathrm{H}, \mathrm{HA}, \mathrm{JAM}=12.5 \mathrm{~Hz}, \mathrm{JAX}=6.5 \mathrm{~Hz}), 6.69-7.73(\mathrm{~m}, 8 \mathrm{H}, \mathrm{Ar}-$ $\mathrm{H}), 7.85$ (bs, 1H, NH-pyrazoline), 10.21 (bs, 1H, NH-indole) ppm; 13C NMR (100 MHz, DMSO-d $\left.{ }_{6}\right): \delta 41.6$ (C-4'), 44.9 (C-5'), 143.6 (C-3'), 110.2, 110.6, 113.1, 118.3, 120.5, 122.8, 126.4, 129.6, 131.0, 136.2, 142.4, 150.7 (aromatic carbons). HRMS (m/z): 274.0956 [M+Na]; Anal. calcd. for $\mathrm{C}_{15} \mathrm{H}_{13} \mathrm{~N}_{3} \mathrm{O}$ : C, $71.70 ; \mathrm{H}, 5.21 ; \mathrm{N}, 16.72 \%$. Found: $\mathrm{C}, 71.83 ; \mathrm{H}, 5.24$; $\mathrm{N}, 16.92 \%$.

3-(Furan-2-yl)-5-(5-fluoro-5-1H-indol-3-yl)-2-pyrazoline (8b): M.p. $178-180^{\circ} \mathrm{C}$, yield 82\%; IR $(\mathrm{KBr})\left(\mathrm{cm}^{-1}\right): 3320(\mathrm{NH}), 1636$ $(\mathrm{C}=\mathrm{C}), 1577(\mathrm{C}=\mathrm{N})$; $1 \mathrm{H}$ NMR $\left(400 \mathrm{MHz}, \mathrm{DMSO}_{-} \mathrm{d}_{6}\right): \delta 3.32(\mathrm{dd}, 1 \mathrm{H}$, $\mathrm{HX}, \mathrm{JAX}=6.8 \mathrm{~Hz}, \mathrm{JMX}=10.9 \mathrm{~Hz}), 4.13(\mathrm{dd}, 1 \mathrm{H}, \mathrm{HM}, \mathrm{JAM}=12.8 \mathrm{~Hz}$, $\mathrm{JMX}=10.9 \mathrm{~Hz}), 4.46(\mathrm{dd}, 1 \mathrm{H}, \mathrm{HA}, \mathrm{JAM}=12.8 \mathrm{~Hz}, \mathrm{JAX}=6.8 \mathrm{~Hz}), 6.73-$ 7.78 (m, 7H, Ar-H), 7.88 (bs, 1H, NH-pyrazoline), 10.32 (bs, 1H, NHindole) ppm; 13C NMR (100 MHz, DMSO-d $\left.{ }_{6}\right): \delta 41.4(\mathrm{C}-4$ '), $44.6(\mathrm{C}-$ $\left.5^{\prime}\right), 143.9$ (C-3'), 113.2, 113.8, 117.4, 119.3, 123.6, 127.1, 129.2, 131.6, 136.8, 143.4, 150.6, 151.3 (aromatic carbons); HRMS (m/z): 292.0862 [M+Na]; Anal. calcd. for $\mathrm{C}_{15} \mathrm{H}_{12} \mathrm{FN}_{3} \mathrm{O}: \mathrm{C} 66.91 ; \mathrm{H}, 4.49 ; \mathrm{N}, 15.60 \%$. Found: C, 67.02; $\mathrm{H}, 4.50 ; \mathrm{N}, 15.78 \%$.

3-(5-Bromothiophen-2-yl)-5-(1H-indol-3-yl)-2-pyrazoline (9a): M.p. $212-214^{\circ} \mathrm{C}$, yield 84\%; IR (KBr) $\left(\mathrm{cm}^{-1}\right): 3328(\mathrm{NH}), 1639$ $(\mathrm{C}=\mathrm{C}), 1584(\mathrm{C}=\mathrm{N})$; $1 \mathrm{H}$ NMR $\left(400 \mathrm{MHz}, \mathrm{DMSO}_{-} \mathrm{d}_{6}\right): \delta 3.34(\mathrm{dd}, 1 \mathrm{H}$, HX, JAX=6.3 Hz, JMX=10.2 Hz), $4.19(\mathrm{dd}, 1 \mathrm{H}, \mathrm{HM}, \mathrm{JAM}=12.4 \mathrm{~Hz}$, $\mathrm{JMX}=10.2 \mathrm{~Hz}), 4.66(\mathrm{dd}, 1 \mathrm{H}, \mathrm{HA}, \mathrm{JAM}=12.4 \mathrm{~Hz}, \mathrm{JAX}=6.3 \mathrm{~Hz}), 6.92-$ 7.68 (m, 7H, Ar-H), 7.82 (bs, 1H, NH-pyrazoline), 10.56 (bs, 1H, NHindole) ppm; 13C NMR (100 MHz, DMSO-d $\left.{ }_{6}\right): \delta 41.7$ (C-4'), 45.1 (C$\left.5^{\prime}\right), 139.4$ (C-3'), 111.3, 112.5, 118.4, 118.7, 120.7, 121.9, 125.3, 127.2, 128.7, 132.3, 134.1, 151.8 (aromatic carbons); HRMS (m/z): 367.9842 $[\mathrm{M}+\mathrm{Na}]$; Anal. calcd. for $\mathrm{C}_{15} \mathrm{H}_{12} \mathrm{BrN}_{3} \mathrm{~S}: \mathrm{C}, 52.03 ; \mathrm{H}, 3.49 ; \mathrm{N}, 12.14 \%$. Found: C, 52.13; H, 3.50; N, 12.36\%.

3-(5-Bromothiophen-2-yl)-5-(5-fluoro-1H-indol-3-yl)-2pyrazoline (9b): M.p. $181-183^{\circ} \mathrm{C}$, yield $82 \%$; IR $(\mathrm{KBr})\left(\mathrm{cm}^{-1}\right): 3324$ $(\mathrm{NH}), 1642(\mathrm{C}=\mathrm{C}), 1577(\mathrm{C}=\mathrm{N}) ; 1$ H NMR $\left(400 \mathrm{MHz}, \mathrm{DMSO}-\mathrm{d}_{6}\right): \delta 3.38$ (dd, 1H, HX, JAX=6.5 Hz, JMX=10.3 Hz), $4.23(\mathrm{dd}, 1 \mathrm{H}, \mathrm{HM}, \mathrm{JAM}=12.3$ $\mathrm{Hz}, \mathrm{JMX}=10.3 \mathrm{~Hz}), 4.68(\mathrm{dd}, 1 \mathrm{H}, \mathrm{HA}, \mathrm{JAM}=12.3 \mathrm{~Hz}, \mathrm{JAX}=6.5 \mathrm{~Hz}$ ), 7.01-7.82 (m, 6H, Ar-H), 7.89 (bs, 1H, NH-pyrazoline), 10.62 (bs, $1 \mathrm{H}$, NH-indole) ppm; 13C NMR (100 MHz, DMSO-d $)$ : $\delta 42.1$ (C-4'), 45.4 (C-5'), 138.9 (C-3'), 117.6, 120.4, 111.8, 113.2, 125.4, 126.7, 128.3, 132.1, 136.4, 140.8, 151.2, 152.4 (aromatic carbons); HRMS (m/z): 385.9739 [M+Na]; Anal. calcd. for $\mathrm{C}_{15} \mathrm{H}_{11} \mathrm{BrFN}_{3} \mathrm{~S}: \mathrm{C}, 49.46 ; \mathrm{H}, 3.04 ; \mathrm{N}, 11.54 \%$. Found: C, 49.58; H, 3.06; N, 11.79\%.

3-(Pyridin-2-yl)-5-(1H-indol-3-yl)-2-pyrazoline (10a): M.p. 227-229 ${ }^{\circ} \mathrm{C}$, yield 83\%; IR (KBr) $\left(\mathrm{cm}^{-1}\right): 3327(\mathrm{NH}), 1646(\mathrm{C}=\mathrm{C}), 1589$ $(\mathrm{C}=\mathrm{N})$; $1 \mathrm{H}$ NMR $\left.(400 \mathrm{MHz}, \text { DMSO-d })_{6}\right) \delta 3.43(\mathrm{dd}, 1 \mathrm{H}, \mathrm{HX}, \mathrm{JAX}=5.5$ $\mathrm{Hz}, \mathrm{JMX}=10.7 \mathrm{~Hz}), 4.10(\mathrm{dd}, 1 \mathrm{H}, \mathrm{HM}, \mathrm{JAM}=11.8 \mathrm{~Hz}, \mathrm{JMX}=10.7 \mathrm{~Hz})$, $4.64(\mathrm{dd}, 1 \mathrm{H}, \mathrm{HA}, \mathrm{JAM}=11.8 \mathrm{~Hz}, \mathrm{JAX}=5.5 \mathrm{~Hz}), 7.14-7.88(\mathrm{~m}, 9 \mathrm{H}, \mathrm{Ar}-$ $\mathrm{H}), 7.91$ (bs, 1H, NH-pyrazoline), 11.63 (bs, 1H, NH-indole) ppm; 13C NMR (100 MHz, DMSO-d $\left.)_{6}\right): \delta 2.6$ (C-4'), 45.6 (C-5'), 142.9 (C-3'), $121.2,137.5,113.1,117.3,123.5,124.7,125.1,127.3,128.6,130.4,151.6$ (aromatic carbons); HRMS (m/z): $285.1116[\mathrm{M}+\mathrm{Na}]$; Anal. calcd. for $\mathrm{C}_{16} \mathrm{H}_{14} \mathrm{~N}_{4}$ : C, 73.26; H, 5.38; N, 21.36\%. Found: C, 73.20; H, 5.36; N, $21.28 \%$.

3-(Pyridin-2-yl)-5-(5-fluoro-1H-indol-3-yl)-2-pyrazoline (10b): M.p. $201-203^{\circ} \mathrm{C}$, yield 79\%; IR (KBr) $\left(\mathrm{cm}^{-1}\right): 3341(\mathrm{NH}), 1643$ $(\mathrm{C}=\mathrm{C}), 1596(\mathrm{C}=\mathrm{N})$; $1 \mathrm{H}$ NMR $\left(400 \mathrm{MHz}, \mathrm{DMSO}-\mathrm{d}_{6}\right): \delta 3.45(\mathrm{dd}, 1 \mathrm{H}$, HX, JAX=5.7 Hz, JMX=10.2 Hz), $4.18(\mathrm{dd}, 1 \mathrm{H}, \mathrm{HM}$, JAM=11.6 Hz, 
$\mathrm{JMX}=10.2 \mathrm{~Hz}), 4.67$ (dd, 1H, HA, JAM=11.6 Hz, JAX=5.7 Hz), 7.237.90 (m, 8H, Ar-H), 7.94 (bs, 1H, NH-pyrazoline), 11.76 (bs, 1H, NHindole) ppm; 13C NMR (100 MHz, DMSO-d $)$ : $\delta 41.5\left(\mathrm{C}-4^{\prime}\right), 45.2\left(\mathrm{C}-5^{\prime}\right)$, 142.3 (C-3'), 121.4, 138.7, 113.4, 117.8, 121.4, 123.7, 127.5, 128.2, 129.9, 151.3, 152.7 (aromatic carbons); HRMS (m/z): 303.1022 [M+Na]; Anal. calcd. for $\mathrm{C}_{16} \mathrm{H}_{13} \mathrm{FN}_{4}$ : C, 68.56; H, 4.67; N, 19.99\%. Found: $\mathrm{C}, 68.66 ; \mathrm{H}$, $4.70 ; \mathrm{N}, 20.18 \%$

General procedure for the synthesis of 3-(furan-2-yl)-5-(1Hindol-3-yl)-2-isoxazoline (14a, b) / 3-(5-bromothiophen-2yl)-5-(1H-indol-3-yl)-2-isoxazoline $(15 \mathrm{a}, \mathrm{b})$ / 3-(pyridin-2yl)-5-(1H-indol-3-yl)-2-isoxazoline (16a, b)

A solution of 5/6/7 (1 mmol), hydroxylamine hydrochloride (1.1 $\mathrm{mmol})$ in ethanol $(6 \mathrm{~mL})$ was kept under ultrasonication at room temperature for 60-70 min. The progress of the reaction was monitored by TLC. After completion of the reaction, the contents of the flask were poured onto crushed ice. It was extracted with dichloromethane. The organic layer was washed with water, brine and dried $\left(\mathrm{an} . \mathrm{Na}_{2} \mathrm{SO}_{4}\right)$. The solvent was removed under reduced pressure. The resultant residue was purified by column chromatography (silica gel, 60-120 mesh) using hexane/ethyl acetate (4:1) as eluent.

3-(Furan-2-yl)-5-(1H-indol-3-yl)-2-isoxazoline (14a): M.p. 168$170^{\circ} \mathrm{C}$, Yield 79\%; IR (KBr) (cm-1): $3335(\mathrm{NH}), 1644(\mathrm{C}=\mathrm{C}), 1588$ $(\mathrm{C}=\mathrm{N})$; $1 \mathrm{H}$ NMR $\left(400 \mathrm{MHz}, \mathrm{DMSO}-\mathrm{d}_{6}\right): \delta 3.26(\mathrm{dd}, 1 \mathrm{H}, \mathrm{HX}, \mathrm{JAX}=6.6$ $\mathrm{Hz}, \mathrm{JMX}=10.5 \mathrm{~Hz}), 4.52(\mathrm{dd}, 1 \mathrm{H}, \mathrm{HM}, \mathrm{JAM}=12.6 \mathrm{~Hz}, \mathrm{JMX}=10.5 \mathrm{~Hz})$, $4.98(\mathrm{dd}, 1 \mathrm{H}, \mathrm{HA}, \mathrm{JAM}=12.6 \mathrm{~Hz}, \mathrm{JAX}=6.8 \mathrm{~Hz}), 6.88-7.87(\mathrm{~m}, 8 \mathrm{H}, \mathrm{Ar}-$ $\mathrm{H}), 10.48$ (bs, $1 \mathrm{H}, \mathrm{NH}$-indole) ppm; 13C NMR (100 MHz, DMSO-d $)_{6}$ : $\delta 42.5$ (C-4'), 45.8 (C-5'), 141.2 (C-3'), 113.8, 117.2, 119.7, 120.8, 122.8, $127.9,129.6,134.5,138.1,140.3,151.6,156.4$ (aromatic carbons); HRMS (m/z): 275.0796 [M+Na]; Anal. calcd. for $\mathrm{C}_{15} \mathrm{H}_{12} \mathrm{~N}_{2} \mathrm{O}_{2}: \mathrm{C}, 71.42$; $\mathrm{H}, 4.79 ; \mathrm{N}, 11.10 \%$. Found: C, 71.51; H, 4.78; N, 11.26\%.

3-(Furan-2-yl)-5-(5-fluoro-1H-indol-3-yl)-2-isoxazoline (14b): M.p. $182-184^{\circ} \mathrm{C}$, yield 81\%; IR (KBr) (cm-1): $3343(\mathrm{NH}), 1635$ $(\mathrm{C}=\mathrm{C}), 1579(\mathrm{C}=\mathrm{N})$; $1 \mathrm{H}$ NMR $\left(400 \mathrm{MHz}, \mathrm{DMSO}_{6} \mathrm{~d}_{6}\right): \delta 3.30(\mathrm{dd}$, $1 \mathrm{H}, \mathrm{HX}, \mathrm{JAX}=6.7 \mathrm{~Hz}, \mathrm{JMX}=10.8 \mathrm{~Hz}), 4.56(\mathrm{dd}, 1 \mathrm{H}, \mathrm{HM}, \mathrm{JAM}=12.7$ $\mathrm{Hz}, \mathrm{JMX}=10.8 \mathrm{~Hz}), 5.08(\mathrm{dd}, 1 \mathrm{H}, \mathrm{HA}, \mathrm{JAM}=12.7 \mathrm{~Hz}, \mathrm{JAX}=6.7 \mathrm{~Hz})$, 6.91-7.89 (m, 7H, Ar-H), 10.53 (bs, 1H, NH-indole) ppm; 13C NMR (100 MHz, DMSO-d $\left.\mathrm{d}_{6}\right): \delta 43.2$ (C-4'), 45.3 (C-5'), 141.6 (C-3'), 113.9, $114.2,119.4,127.7,129.3,134.5,138.4,138.8,151.6,140.6,151.5,158.1$ (aromatic carbons); HRMS (m/z): $293.0708[\mathrm{M}+\mathrm{Na}]$; Anal. calcd. for $\mathrm{C}_{15} \mathrm{H}_{11} \mathrm{FN}_{2} \mathrm{O}: \mathrm{C}, 66.66 ; \mathrm{H}, 4.10 ; \mathrm{N}, 10.37 \%$. Found: $\mathrm{C}, 66.61 ; \mathrm{H}, 4.12 ; \mathrm{N}$, $10.40 \%$.

3-(5-Bromothiophen-2-yl)-5-(1H-indol-3-yl)-2-isoxazoline (15a): M.p. $217-218^{\circ} \mathrm{C}$, yield 78\%; IR (KBr) (cm-1): $3332(\mathrm{NH}), 1637$ $(\mathrm{C}=\mathrm{C}), 1587(\mathrm{C}=\mathrm{N})$; $1 \mathrm{H}$ NMR $\left(400 \mathrm{MHz}, \mathrm{DMSO}-\mathrm{d}_{6}\right): \delta 3.41(\mathrm{dd}$, $1 \mathrm{H}, \mathrm{HX}, \mathrm{JAX}=5.8 \mathrm{~Hz}, \mathrm{JMX}=10.6 \mathrm{~Hz}), 4.57(\mathrm{dd}, 1 \mathrm{H}, \mathrm{HM}, \mathrm{JAM}=12.4$ $\mathrm{Hz}, \mathrm{JMX}=10.6 \mathrm{~Hz}), 5.12(\mathrm{dd}, 1 \mathrm{H}, \mathrm{HA}, \mathrm{JAM}=12.4 \mathrm{~Hz}, \mathrm{JAX}=5.8 \mathrm{~Hz}$ ), 7.12-8.09 (m, 7H, Ar-H), 10.71 (bs, 1H, NH-indole) ppm; 13C NMR (100 MHz, DMSO-d $\left.\mathrm{d}_{6}\right): \delta 41.8$ (C-4'), 45.7 (C-5'), 140.2 (C-3'), 114.2, 114.6, 117.3, 120.2, 121.8, 123.5, 125.7, 127.0, 128.5, 130.6, 139.3, 151.8 (aromatic carbons); HRMS (m/z): $368.9681[\mathrm{M}+\mathrm{Na}]$; Anal. calcd. for $\mathrm{C}_{15} \mathrm{H}_{11} \mathrm{BrN}_{2} \mathrm{OS}$ : C, 51.89; H, 3.19; N, 8.07\%. Found: C, 51.97; H, 3.18; $\mathrm{N}, 8.25 \%$.

3-(5-Bromothiophen-2-yl)-5-(5-fluoro-1H-indol-3-yl)-2isoxazoline (15b): M.p. $187-189^{\circ} \mathrm{C}$, yield $80 \%$; IR (KBr) (cm-1): 3336 $(\mathrm{NH}), 1632(\mathrm{C}=\mathrm{C}), 1584(\mathrm{C}=\mathrm{N}) ; 1 \mathrm{H}$ NMR $\left(400 \mathrm{MHz}, \mathrm{DMSO}-\mathrm{d}_{6}\right): \delta$ $3.47(\mathrm{dd}, 1 \mathrm{H}, \mathrm{HX}, \mathrm{JAX}=5.8 \mathrm{~Hz}, \mathrm{JMX}=10.6 \mathrm{~Hz}), 4.57(\mathrm{dd}, 1 \mathrm{H}, \mathrm{HM}$, JAM $=12.4 \mathrm{~Hz}, J M X=10.6 \mathrm{~Hz}), 5.12(\mathrm{dd}, 1 \mathrm{H}, \mathrm{HA}, \mathrm{JAM}=12.4 \mathrm{~Hz}$, $\mathrm{JAX}=5.8 \mathrm{~Hz}), 7.12-8.09(\mathrm{~m}, 6 \mathrm{H}, \mathrm{Ar}-\mathrm{H}), 10.78$ (bs, $1 \mathrm{H}, \mathrm{NH}$-indole) ppm;
13C NMR (100 MHz, DMSO-d $): \delta 41.4$ (C-4'), 45.9 (C-5'), 140.7 (C$\left.3^{\prime}\right)$, 117.6, 117.9, 117.8, 118.3, 120.9, 123.8, 128.0, 129.1, 136.6, 139.5, 152.0, 152.3 (aromatic carbons); HRMS (m/z): 386.9579 [M+Na]; Anal. calcd. for $\mathrm{C}_{15} \mathrm{H}_{10} \mathrm{BrFN}_{2} \mathrm{OS}$ : C, 49.33; H, 2.76; N, 7.67\%. Found: C, 49.44; $\mathrm{H}, 2.79$; $\mathrm{N}, 7.90 \%$.

3-(Pyridin-2-yl)-5-(1H-indol-3-yl)-2-isoxazoline (16a): M.p. 216-218 ${ }^{\circ} \mathrm{C}$, yield 86\%; IR (KBr) $(\mathrm{cm}-1): 3338(\mathrm{NH}), 1631(\mathrm{C}=\mathrm{C}), 1585$ $(\mathrm{C}=\mathrm{N}) ; 1 \mathrm{H}$ NMR $\left(400 \mathrm{MHz}, \mathrm{DMSO}-\mathrm{d}_{6}\right): \delta 3.52(\mathrm{dd}, 1 \mathrm{H}, \mathrm{HX}, \mathrm{JAX}=6.2$ $\mathrm{Hz}, \mathrm{JMX}=10.8 \mathrm{~Hz}), 4.62(\mathrm{dd}, 1 \mathrm{H}, \mathrm{HM}, \mathrm{JAM}=12.2 \mathrm{~Hz}, \mathrm{JMX}=10.8 \mathrm{~Hz})$, $5.20(\mathrm{dd}, 1 \mathrm{H}, \mathrm{HA}, \mathrm{JAM}=12.2 \mathrm{~Hz}, \mathrm{JAX}=6.2 \mathrm{~Hz}), 7.26-8.24(\mathrm{~m}, 9 \mathrm{H}, \mathrm{Ar}-$ $\mathrm{H}), 11.96$ (bs, $1 \mathrm{H}, \mathrm{NH}$-indole) ppm; 13C NMR (100 MHz, DMSO-d $)$ : $\delta 42.4\left(\mathrm{C}^{-} 4^{\prime}\right), 45.8$ (C-5'), 140.1 (C-3'), 123.3, 136.9, 113.7, 117.1, 121.5, $124.9,126.4,127.7,129.0,140.3,151.5$ (aromatic carbons); HRMS $(\mathrm{m} / \mathrm{z}): 286.0956$ [M+Na]; Anal. calcd. for $\mathrm{C}_{16} \mathrm{H}_{13} \mathrm{~N}_{3} \mathrm{O}: \mathrm{C}, 72.99 ; \mathrm{H}, 4.98$; $\mathrm{N}, 15.96 \%$. Found: C, 73.11; H, 4.96; N, 16.22\%.

3-(Pyridin-2-yl)-5-(5-fluoro-1 H-indol-3-yl)-2-isoxazoline (16b): M.p. 186-188 ${ }^{\circ} \mathrm{C}$, yield 82\%; IR (KBr) (cm-1): $3335(\mathrm{NH}), 1633$

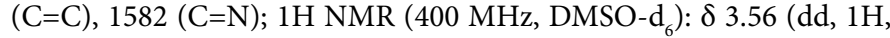
HX, JAX $=6.4 \mathrm{~Hz}, \mathrm{JMX}=10.5 \mathrm{~Hz}), 4.65(\mathrm{dd}, 1 \mathrm{H}, \mathrm{HM}, \mathrm{JAM}=12.2 \mathrm{~Hz}$ $\mathrm{JMX}=10.5 \mathrm{~Hz}), 5.23(\mathrm{dd}, 1 \mathrm{H}, \mathrm{HA}, \mathrm{JAM}=12.2 \mathrm{~Hz}, \mathrm{JAX}=6.4 \mathrm{~Hz}), 7.31-$ 8.27 (m, 8H, Ar-H), 11.98 (bs, 1H, NH-indole) ppm; 13C NMR (100 MHz, DMSO-d $): \delta 42.7$ (C-4'), 45.5 (C-5'), 141.6 (C-3'), 123.9, 138.5, $117.7,121.0,124.7,126.8,127.6,128.8,129.2,151.9,152.3$ (aromatic carbons); HRMS (m/z): $304.0862[\mathrm{M}+\mathrm{Na}]$; Anal. calcd. for $\mathrm{C}_{16} \mathrm{H}_{12} \mathrm{FN}_{3} \mathrm{O}$ : C, $68.32 ; \mathrm{H}, 4.30 ; \mathrm{N}, 14.94 \%$. Found: C, $68.41 ; \mathrm{H}, 4.32 ; \mathrm{N}, 15.14 \%$.

General procedure for the synthesis of 3,5-diaryl pyrazoles (11 a, b / 12 a, b / 13 a, b) and 3,5-diaryl isoxazoles (17 a, b / 18 a, b / 19 a, b)

A solution of $8 / 9 / 10 / 14 / 15 / 16(1 \mathrm{mmol})$ in xylene $(7 \mathrm{~mL})$ and chloranil $(1.2 \mathrm{mmol})$ were subjected to ultrasonication at reflux temperature for 1-2 hrs. Then, it was treated with $5 \% \mathrm{NaOH}$ solution. The organic layer was separated and repeatedly washed with water and dried ( $\left.\mathrm{an} . \mathrm{Na}_{2} \mathrm{SO}_{4}\right)$. The solvent was removed in vaccuo. The solid obtained was purified by recrystallization from 2-propanol.

3-(Furan-2-yl)-5-(1H-indol-3-yl)pyrazole (11a): M.p. 212-214 ${ }^{\circ} \mathrm{C}$ yield 73\%; IR $(\mathrm{KBr})\left(\mathrm{cm}^{-1}\right): 3342(\mathrm{NH}), 1638(\mathrm{C}=\mathrm{C}), 1575(\mathrm{C}=\mathrm{N}) ; 1 \mathrm{H}$ NMR (400 MHz, DMSO-d $\left.{ }_{6}\right): \delta 6.83-7.72(\mathrm{~m}, 9 \mathrm{H}, \mathrm{Ar}-\mathrm{H}), 7.63$ (bs, $1 \mathrm{H}$, NH-pyrazole), 10.46 (bs, 1H, NH-indole) ppm; 13C NMR (100 MHz, DMSO-d $\left.{ }_{6}\right): \delta 108.3$ (C-4'), $131.0\left(\mathrm{C}-5^{\prime}\right), 132.5\left(\mathrm{C}-3^{\prime}\right), 109.8,110.6,111.4$ 112.8, 113.2, 118.7, 120.9, 125.3, 125.7, 134.6, 141.1, 152.5 (aromatic carbons); HRMS (m/z): $272.0800[\mathrm{M}+\mathrm{Na}]$; Anal. calcd. for $\mathrm{C}_{15} \mathrm{H}_{11} \mathrm{~N}_{3} \mathrm{O}$ : C, $72.28 ; \mathrm{H}, 4.45 ; \mathrm{N}, 16.86 \%$. Found: $\mathrm{C}, 72.22 ; \mathrm{H}, 4.48 ; \mathrm{N}, 17.02 \%$.

3-(Furan-2-yl)-5-(5-fluoro-1H-indol-3-yl)pyrazole (11b): M.p. 183-185 ${ }^{\circ} \mathrm{C}$, yield 75\%; IR $(\mathrm{KBr})\left(\mathrm{cm}^{-1}\right): 3337(\mathrm{NH}), 1648(\mathrm{C}=\mathrm{C}), 1598$ $(\mathrm{C}=\mathrm{N}) ; 1 \mathrm{H}$ NMR $\left(400 \mathrm{MHz}, \mathrm{DMSO}-\mathrm{d}_{6}\right): \delta 6.94-7.67(\mathrm{~m}, 8 \mathrm{H}, \mathrm{Ar}-\mathrm{H})$, 7.68 (bs, 1H, NH-pyrazole), 10.53 (bs, 1H, NH-indole) ppm; 13C NMR (100 MHz, DMSO-d $)$ : $\delta 108.1$ (C-4'), 131.3 (C-5'), 132.7 (C-3'), 110.4, $110.7,110.9,113.3,113.6,117.8,124.3,125.5,134.8,141.6,153.1,157.4$ (aromatic carbons); HRMS (m/z): $290.0706[\mathrm{M}+\mathrm{Na}]$; Anal. calcd. for $\mathrm{C}_{15} \mathrm{H}_{10} \mathrm{FN}_{3} \mathrm{O}: \mathrm{C}, 67.41 ; \mathrm{H}, 3.77 ; \mathrm{N}, 15.72 \%$. Found: C, 67.49; H, 3.78; N, $15.91 \%$.

3-(5-Bromothiophen-2-yl)-5-(1H-indol-3-yl)pyrazole (12a): M.p. $217-219^{\circ} \mathrm{C}$, yield 73\%; IR $(\mathrm{KBr})\left(\mathrm{cm}^{-1}\right): 3342(\mathrm{NH}), 1647(\mathrm{C}=\mathrm{C})$, $1594(\mathrm{C}=\mathrm{N}) ; 1 \mathrm{H}$ NMR $\left(400 \mathrm{MHz}, \mathrm{DMSO}-\mathrm{d}_{6}\right): \delta$ 7.32-7.71 (m, 8H, Ar$\mathrm{H}), 7.84$ (bs, 1H, NH-pyrazole), 10.84 (bs, 1H, NH-indole) ppm; 13C NMR (100 MHz, DMSO-d $\left.{ }_{6}\right): \delta 109.1$ (C-4'), 130.6 (C-5'), 133.5 (C-3'), $111.0,112.2,112.8,114.2,120.5,121.9,122.5,124.3,132.4,136.9,142.4$ 
153.4 (aromatic carbons); HRMS (m/z): 365.9681 [M+Na]; Anal. calcd. for $\mathrm{C}_{15} \mathrm{H}_{10} \mathrm{BrN}_{3} \mathrm{~S}$ : C, 52.34; H, 2.93; N, 12.21\%. Found: C, 52.44; H, 2.92; $\mathrm{N}, 12.45 \%$.

3-(5-Bromothiophen-2-yl)-5-(5-fluoro-1H-indol-3-yl)pyrazole (12b): M.p. $184-186^{\circ} \mathrm{C}$, yield $70 \%$; IR $(\mathrm{KBr})\left(\mathrm{cm}^{-1}\right): 3346(\mathrm{NH}), 1640$ $(\mathrm{C}=\mathrm{C}), 1583(\mathrm{C}=\mathrm{N})$; $1 \mathrm{H}$ NMR $\left(400 \mathrm{MHz}, \mathrm{DMSO}-\mathrm{d}_{6}\right): \delta$ 7.41-7.78 $(\mathrm{m}$, 7H, Ar-H), 7.79 (bs, $1 \mathrm{H}, \mathrm{NH}$-pyrazole), 10.86 (bs, $1 \mathrm{H}, \mathrm{NH}$-indole) ppm; 13C NMR (100 MHz, DMSO-d $)$ : $\delta 108.6$ (C-4'), 131.8 (C-5'), 133.3 (C$\left.3^{\prime}\right), 110.2,111.7,112.4,113.8,114.6,122.2,123.1,124.5,135.3,142.7$, 153.8, 157.6 (aromatic carbons); HRMS (m/z): 383.9582 [M+Na]; Anal. calcd. for $\mathrm{C}_{15} \mathrm{H}_{9} \mathrm{BrFN}_{3} \mathrm{~S}$ : C, 49.74; $\mathrm{H}, 2.50 ; \mathrm{N}, 11.60 \%$. Found: $\mathrm{C}, 49.82$; $\mathrm{H}, 2.52 ; \mathrm{N}, 11.79 \%$.

3-(Pyridin-2-yl)-5-(1H-indol-3-yl)pyrazole (13a): M.p. 220$222^{\circ} \mathrm{C}$, yield 76\%; IR $(\mathrm{KBr})\left(\mathrm{cm}^{-1}\right): 3344(\mathrm{NH}), 1649(\mathrm{C}=\mathrm{C}), 1596(\mathrm{C}=\mathrm{N})$; $1 \mathrm{H}$ NMR (400 MHz, DMSO-d $\left.{ }_{6}\right): \delta 7.20-8.03(\mathrm{~m}, 10 \mathrm{H}, \mathrm{Ar}-\mathrm{H}), 7.84$ (bs, $1 \mathrm{H}, \mathrm{NH}-$ pyrazole), 11.21 (bs, $1 \mathrm{H}, \mathrm{NH}$-indole) ppm; 13C NMR (100 MHz, DMSO-d $\mathrm{d}_{6}$ : $\delta 109.2$ (C-4'), $131.4\left(\mathrm{C}-5^{\prime}\right), 133.2$ (C-3'), 110.3, 112.7, 111.6, 114.3, 120.1, 121.4, 122.2, 125.1, 134.6, 139.1, 148.4 (aromatic carbons); HRMS (m/z): $283.0960[\mathrm{M}+\mathrm{Na}]$; Anal. calcd. for $\mathrm{C}_{16} \mathrm{H}_{12} \mathrm{~N}_{4}: \mathrm{C}$, $73.83 ; \mathrm{H}, 4.65 ; \mathrm{N}, 21.52 \%$. Found: $\mathrm{C}, 73.92 ; \mathrm{H}, 4.68 ; \mathrm{N}, 21.73 \%$.

3-(Pyridin-2-yl)-5-(5-fluoro-1H-indol-3-yl)pyrazole (13b): M.p. 208-210 ${ }^{\circ} \mathrm{C}$; yield 73\%; IR (KBr) (cm-1): $3348(\mathrm{NH}), 1656(\mathrm{C}=\mathrm{C}), 1591$ $(\mathrm{C}=\mathrm{N}) ; 1 \mathrm{H}$ NMR $\left(400 \mathrm{MHz}, \mathrm{DMSO}-\mathrm{d}_{6}\right): \delta$ 7.25-8.09 (m, 9H, Ar-H), 7.87 (bs, $1 \mathrm{H}, \mathrm{NH}$-pyrazole), 11.28 (bs, $1 \mathrm{H}, \mathrm{NH}$-indole) ppm; 13C NMR (100 MHz, DMSO-d $\left.{ }_{6}\right): \delta 109.5$ (C-4'), 131.9 (C-5'), 133.5 (C-3'), $110.9,112.4,114.6,120.6,122.7,125.3,125.5,135.7,139.4,148.9,157.3$ (aromatic carbons); HRMS (m/z): $301.0865[\mathrm{M}+\mathrm{Na}]$; Anal. calcd. for $\mathrm{C}_{16} \mathrm{H}_{11} \mathrm{FN}_{4}: \mathrm{C}, 69.06 ; \mathrm{H}, 3.98 ; \mathrm{N}, 20.13 \%$. Found: $\mathrm{C}, 69.17 ; \mathrm{H}, 4.01 ; \mathrm{N}$, $20.36 \%$.

3-(Furan-2-yl)-5-(1H-indol-3-yl)isoxazole (17a): M.p. 174$176^{\circ} \mathrm{C}$, yield 79\%; IR $(\mathrm{KBr})\left(\mathrm{cm}^{-1}\right): 3334(\mathrm{NH}), 1644(\mathrm{C}=\mathrm{C}), 1588$ $(\mathrm{C}=\mathrm{N})$; $1 \mathrm{H}$ NMR (400 MHz, DMSO-d $): \delta$ 6.91-7.69 (m, 9H, Ar-H), 10.72 (bs, $1 \mathrm{H}, \mathrm{NH}$-indole) ppm; 13C NMR (100 MHz, DMSO-d $): \delta$ 108.5 (C-4'), 131.6 (C-5'), 132.3 (C-3'), 110.2, 111.4, 112.5, 112.7, 113.9, $120.5,120.3,121.1,132.4,133.9,141.2,152.7$, (aromatic carbons); HRMS (m/z): $273.0649[\mathrm{M}+\mathrm{Na}]$; Anal. calcd. for $\mathrm{C}_{15} \mathrm{H}_{10} \mathrm{~N}_{2} \mathrm{O}_{2}: \mathrm{C}, 71.99$; H, 4.03; N, 11.19\%. Found: C, 72.12; H, 4.08; N, 11.47\%.

3-(Furan-2-yl)-5-(5-fluoro-1H-indol-3-yl)isoxazole (17b): M.p. 187-188 ${ }^{\circ} \mathrm{C}$, yield 77\%; IR $(\mathrm{KBr})\left(\mathrm{cm}^{-1}\right): 3338(\mathrm{NH}), 1639(\mathrm{C}=\mathrm{C}), 1585$ $(\mathrm{C}=\mathrm{N})$; $1 \mathrm{H}$ NMR $\left(400 \mathrm{MHz}, \mathrm{DMSO}-\mathrm{d}_{6}\right): \delta 7.01-7.72(\mathrm{~m}, 8 \mathrm{H}, \mathrm{Ar}-\mathrm{H})$, 10.78 (bs, $1 \mathrm{H}, \mathrm{NH}$-indole) ppm; 13C NMR (100 MHz, DMSO-d $)$ : $\delta 108.9$ (C-4'), 132.0 (C-5'), 132.9 (C-3'), 109.8, 110.5, 111.7, 113.4, $113.9,118.1,125.6,126.4,135.2,141.9,153.5,157.2$ (aromatic carbons); HRMS (m/z): $291.0546\left[\mathrm{M}+\mathrm{Na}\right.$ ]; Anal. calcd. for $\mathrm{C}_{15} \mathrm{H}_{9} \mathrm{FN}_{2} \mathrm{O}_{2}: \mathrm{C}, 67.16$; H, 3.38; N, 10.44\%. Found: C, 67.27; H, 3.41; N, 10.66\%.

3-(5-Bromothiophen-2-yl)-5-(1H-indol-3-yl)isoxazole (18a): M.p. $221-223^{\circ} \mathrm{C}$, yield 74\%; IR (KBr) (cm-1): $3341(\mathrm{NH}), 1655(\mathrm{C}=\mathrm{C})$, $1592(\mathrm{C}=\mathrm{N})$; $1 \mathrm{H}$ NMR $\left(400 \mathrm{MHz}, \mathrm{DMSO}_{-} \mathrm{d}_{6}\right): \delta$ 7.21-7.85 (m, 8H, ArH), 10.89 (bs, 1H, NH-indole) ppm; 13C NMR (100 MHz, DMSO-d ${ }_{6}$ : $\delta 108.7$ (C-4'), 132.1 (C-5'), $133.4\left(\mathrm{C}^{\prime} 3^{\prime}\right), 110.5,111.9,112.3,113.8$, $118.4,121.1,122.8,126.3,132.4,136.0,143.2,154.0$ (aromatic carbons); HRMS (m/z): 366.9517 [M+Na]; Anal. calcd. for $\mathrm{C}_{15} \mathrm{H}_{9} \mathrm{BrN}_{2} \mathrm{OS}: \mathrm{C}$, $52.19 ; \mathrm{H}, 2.63 ; \mathrm{N}, 8.11 \%$. Found: C, 52.31; H, 2.67; N, 8.36\%.

3-(5-Bromothiophen-2-yl)-5-(5-fluoro-1H-indol-3-yl)isoxazole (18b): M.p. 204-206 ${ }^{\circ} \mathrm{C}$, yield 78\%; IR $(\mathrm{KBr})\left(\mathrm{cm}^{-1}\right): 3339(\mathrm{NH}), 1651$ $(\mathrm{C}=\mathrm{C}), 1589(\mathrm{C}=\mathrm{N})$; $1 \mathrm{H}$ NMR $\left(400 \mathrm{MHz}, \mathrm{DMSO}^{\left.-\mathrm{d}_{6}\right): \delta}\right.$ 7.29-7.87 (m, $7 \mathrm{H}, \mathrm{Ar}-\mathrm{H}), 10.94$ (bs, $1 \mathrm{H}, \mathrm{NH}$-indole) ppm; 13C NMR $(100 \mathrm{MHz}$, DMSO-d $\left.{ }_{6}\right): \delta 109.2$ (C-4'), 132.7 (C-5'), 133.8 (C-3'), 111.2, 112.0,
$112.7,114.2,118.7,121.8,123.1,127.3,136.3,143.6,154.5,157.9$ (aromatic carbons); HRMS (m/z): $384.9422[\mathrm{M}+\mathrm{Na}]$; Anal. calcd. for $\mathrm{C}_{15} \mathrm{H}_{8} \mathrm{BrFN}_{2} \mathrm{OS}: \mathrm{C}, 49.60 ; \mathrm{H}, 2.22 ; \mathrm{N}, 7.71 \%$. Found: $\mathrm{C}, 49.53 ; \mathrm{H}, 2.23$; $\mathrm{N}, 7.86 \%$

3-(Pyridin-2-yl)-5-(1H-indol-3-yl)isoxazole (19a): M.p. 224$226^{\circ} \mathrm{C}$; yield 71\%; IR $(\mathrm{KBr})\left(\mathrm{cm}^{-1}\right): 3343(\mathrm{NH}), 1657(\mathrm{C}=\mathrm{C}), 1595$ $(\mathrm{C}=\mathrm{N})$; $1 \mathrm{H}$ NMR $\left(400 \mathrm{MHz}, \mathrm{DMSO}-\mathrm{d}_{6}\right): \delta$ 7.32-8.14 (m, 10H, Ar-H), 11.34 (bs, $1 \mathrm{H}, \mathrm{NH}$-indole) ppm; 13C NMR (100 MHz, DMSO-d $)$ : $\delta$ 109.6 (C-4'), 132.3 (C-5'), 133.6 (C-3'), 110.4, 111.6, 111.9, 114.5, 120.7, $121.8,122.5,125.3,134.8,139.2,149.4$ (aromatic carbons); HRMS $(\mathrm{m} / \mathrm{z}): 284.0800[\mathrm{M}+\mathrm{Na}]$; Anal. calcd. for $\mathrm{C}_{16} \mathrm{H}_{11} \mathrm{~N}_{3} \mathrm{O}: \mathrm{C}, 73.55 ; \mathrm{H}, 4.24$; N, $16.08 \%$. Found: C, 73.64; H, 4.26; N, 16.26\%.

3-(Pyridin-2-yl)-5-(5-fluoro-1H-indol-3-yl)isoxazole (19b): M.p. 198-200 ${ }^{\circ} \mathrm{C}$, yield 69\%; IR (KBr) $(\mathrm{cm}-1): 3345(\mathrm{NH}), 1653(\mathrm{C}=\mathrm{C}), 1598$ $(\mathrm{C}=\mathrm{N}) ; 1 \mathrm{H}$ NMR $\left(400 \mathrm{MHz}, \mathrm{DMSO}-\mathrm{d}_{6}\right): \delta$ 7.36-8.17 (m, 9H, Ar-H), 11.37 (bs, $1 \mathrm{H}, \mathrm{NH}$-indole) ppm; 13C NMR (100 MHz, DMSO-d $)_{6}: \delta$ 109.8 (C-4'), 132.5 (C-5'), 133.9 (C-3'), 111.2, 113.1, 114.8, 121.4, 122.9, $125.8,126.0,136.3,139.8,149.2,157.6$ (aromatic carbons); HRMS $(\mathrm{m} / \mathrm{z}): 302.0706[\mathrm{M}+\mathrm{Na}]$; Anal. calcd. for $\mathrm{C}_{16} \mathrm{H}_{10} \mathrm{FN}_{3} \mathrm{O}: \mathrm{C}, 68.81 ; \mathrm{H}$, $3.61 ; \mathrm{N}, 15.05 \%$. Found: C, 68.74; H, 3.60; N, 15.21\%.

\section{Antimicrobial Testing}

The compounds 8-19 were dissolved in DMSO at different concentrations of 50 and $100 \mu \mathrm{g} /$ well.

\section{Cells}

Bacterial strains $S$. aureus, B. subtilis, $P$. aeruginosa, $K$. pneumoniae and fungi $A$. niger, $P$. chrysogenum were obtained from Department of Applied Microbiology, Sri Padmavathi Mahila Visvavidyalayam, Tirupati.

\section{Antibacterial and antifungal assays}

The in vitro antimicrobial studies were carried out by agar well diffusion method against test organisms $[35,36]$. Nutrient broth (NB) plates were swabbed with $24 \mathrm{~h}$ old broth culture $(100 \mu \mathrm{l})$ of test bacteria. Using the sterile cork borer, wells $(6 \mathrm{~mm})$ were made into each petriplate. Various concentrations of DMSO dissolved compounds $(50,100 \mu \mathrm{g} /$ well) were added into the wells by using sterile pipettes. Simultaneously the standard antibiotics, Chloramphenicol for antibacterial activity and Ketoconazole for antifungal activity (as positive control) were tested against the pathogens. The samples were dissolved in DMSO which showed no zone of inhibition acts as negative control. The plates were incubated at $37^{\circ} \mathrm{C}$ for $24 \mathrm{~h}$ for bacteria and at $28^{\circ} \mathrm{C}$ for $48 \mathrm{~h}$ for fungi. After appropriate incubation, the diameter of zone of inhibition of each well was measured. Duplicates were maintained and the average values were calculated for eventual antibacterial activity.

Broth dilution test was used to determine minimum inhibitory concentration (MIC) of the above mentioned samples [37,38]. Freshly prepared nutrient broth was used as diluents. The $24 \mathrm{~h}$ old culture of the test bacteria $S$. aureus, B. subtilis, $P$. aeruginosa, $K$. pneumoniae and fungi $A$. niger, $P$. chrysogenum were diluted 100 folds in nutrient broth $(100 \mu \mathrm{l}$ bacterial cultures in $10 \mathrm{ml} \mathrm{NB})$. Increasing concentrations of the test samples $(1.25,2.5,5,10,20,40 \mu \mathrm{l}$ of stock solution contains $6.25,12.5,25,50,100,200 \mu \mathrm{g} /$ well of the compounds) were added to the test tubes containing the bacterial and fungal cultures. All the tubes were incubated at $37^{\circ} \mathrm{C}$ for $24 \mathrm{~h}$ for bacteria and at $28^{\circ} \mathrm{C}$ for $48 \mathrm{~h}$ for fungi. The tubes were examined for visible turbidity using $\mathrm{NB}$ as control. Control without test samples and with solvent was assayed simultaneously. The lowest concentration that inhibited visible 
growth of the tested organisms was recorded as MIC. To determine the minimum bactericidal concentration (MBC) [39] and minimum fungicidal concentration (MFC) [40] for each set of test tubes in the MIC determination, a loopful of broth was collected from those tubes which did not show any growth and inoculated on sterile nutrient broth (for bacteria) and PDA (for fungi) by streaking. Plates inoculated with bacteria and fungi were incubated at $37^{\circ} \mathrm{C}$ for $24 \mathrm{~h}$ and at $28^{\circ} \mathrm{C}$ for 48 $h$, respectively. After incubation, the lowest concentration was noted as MBC (for bacteria) or MFC (for fungi) at which no visible growth was observed.

\section{Results and Discussion}

\section{Chemistry}

The Michael acceptors (E)-1-(furan-2-yl)-3-(1H-indol-3-yl) prop-2-en-1-one (5), (E)-1-(5-bromothiophen-2-yl)-3-(1H-indol-3yl)prop-2-en-1-one (6) and (E)-3-(1H-indol-3-yl)-1-(pyridin-4-yl) prop-2-en-1-one (7) were utilized as synthons to synthesize a new class of 3,5-disubstituted pyrazoles and isoxazoles. The synthetic intermediates $\mathbf{5}, \mathbf{6}$ and $\mathbf{7}$ were in turn obtained by the Claisen-Schimdt reaction of indole-3-carboxaldehyde (1) with 2-acetylfuran (2) / 2-acetyl-5-bromothiophene (3) / 4-acetylpyridine (4) in the presence of diisopropylethylamine (DIPEA) in methanol under ultrasonication (Scheme 1). It was observed that these compounds were obtained in shorter reaction times with high yield in ultrasonication method when compared with the conventional method. The ${ }^{1} \mathrm{H}$ NMR spectra of compounds $5 \mathbf{a}, \mathbf{6 a}$ and $7 \mathbf{a}$ exhibited two doublets were observed at $6.93,7.21,7.23$ and $8.02,8.15,8.17$ which were accounted to olefin protons $\mathrm{H}_{\mathrm{A}}$ and $\mathrm{H}_{\mathrm{B}}$. The coupling constant values $\mathrm{J}_{\mathrm{AB}}=15.4,15.6$ and $15.9 \mathrm{~Hz}$ revealed that they possess trans geometry. In addition to these, a broad singlet was observed at 11.74, 11.94 and $12.01 \mathrm{ppm}$ was assigned to $\mathrm{NH}$ which disappeared on deuteration. The enone moiety present in $\mathbf{5}$ / $\mathbf{6}$ / $\mathbf{7}$ was exploited to develop pyrazoline and isoxazoline rings adopting [2+3] cyclocondensation. Thus, the cyclocondensation reaction of compounds 5,6 and 7 with hydrazine hydrate under ultrasonication furnished 3-(furan-2-yl)-5-(1H-indol3-yl)-2-pyrazoline (8), 3-(5-bromothiophen-2-yl)-5-(1H-indol-3-yl)2-pyrazoline (9) and 3-(pyridin-2-yl)-5-(1H-indol-3-yl)-2-pyrazoline (10) respectively (Scheme 2 ). The ${ }^{1} \mathrm{H}$ NMR spectra of compounds $\mathbf{8 a}$, 9a and 10a displayed an AMX splitting pattern due to methine and methylene protons of pyrazoline ring. Thus the three double doublets present at $\delta 4.43,4.28,3.24$ in $8 \mathbf{a}$; at 4.66, 4.19, 3.34 in $9 \mathbf{a}$ and at 4.64, 4.10, $3.43 \mathrm{ppm}$ in 10a were accounted to $\mathrm{H}_{\mathrm{A}}, \mathrm{H}_{\mathrm{M}}$ and $\mathrm{H}_{\mathrm{X}}$, respectively. Moreover, two broad singlets appeared at $\delta 7.85,7.82$ and 7.91 and at $10.21,10.56$ and $11.63 \mathrm{ppm}$ were assigned to $\mathrm{NH}$ of pyrazoline and indole rings in addition to signals due to aromatic protons. The signals due to $\mathrm{NH}$ disappeared on deuteration. The oxidation of compounds 8, 9 and 10 with chloranil in xylene provided 3-(furan-2-yl)-5-(1H-indol-3-yl) pyrazole (11), 3-(5-bromothiophen-2-yl)-5-(1H-indol-3-yl)pyrazole (12) and 3-(pyridin-2-yl)-5-(1H-indol-3-yl)pyrazole (13), respectively. The absence of an AMX splitting pattern due to pyrazoline ring protons in the ${ }^{1} \mathrm{H}$ NMR spectra of compounds 11a, 12a and 13a indicated that aromatization occurred. The singlets corresponding to $\mathrm{C}_{4^{\prime}}-\mathrm{H}$ of pyrazole appeared at downfield region and merged with aromatic protons. Apart

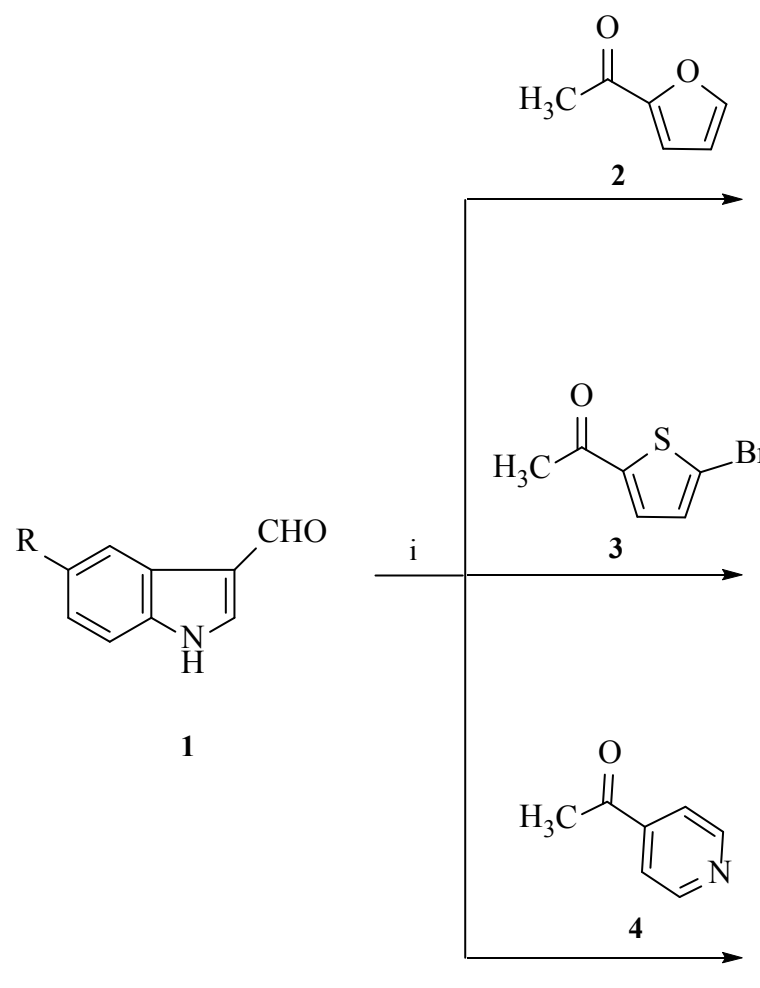

i. DIPEA / $\mathrm{MeOH} /$ )))<smiles>[R]c1ccc2[nH]cc(/C=C(\C)C(=O)c3ccco3)c2c1</smiles><smiles>[R]c1ccc2[nH]cc(/C=C(\C)C(=O)c3ccc(Br)s3)c2c1</smiles><smiles>[R]c1ccc2[nH]cc(/C=C/C(=O)c3ccncc3)c2c1</smiles>

$\mathrm{R}=$ a) $\mathrm{H}$

b) $\mathrm{F}$

Scheme 1: Synthesis of $(E)-1-(\operatorname{aryl})-3-(1 H$-indol-3-yl)prop-2-en-1-ones. 
5<smiles>[R]c1ccc2[nH]cc(C3CC(c4ccco4)=NN3)c2c1</smiles>

8

6<smiles></smiles>

9<smiles>[R]c1ccc2[nH]cc(C3CC(c4ccncc4)=NN3)c2c1</smiles>

10<smiles>[R]c1ccc2[nH]cc(-c3ccn[nH]3)c2c1</smiles>

11<smiles>[R]c1ccc2[nH]cc(-c3cc(-c4ccc(Br)s4)n[nH]3)c2c1</smiles>

12<smiles>[R]c1ccc2[nH]cc(-c3cc(-c4ccncc4)n[nH]3)c2c1</smiles>

13

(i) $\mathrm{NH}_{2} \mathrm{NH}_{2} \cdot \mathrm{H}_{2} \mathrm{O} / \mathrm{EtOH} /$ )))

(ii) Chloranil / Xylene / ))) 
<smiles>[R]c1ccc2[nH]cc(C3CC(c4ccco4)=NO3)c2c1</smiles><smiles></smiles>

15<smiles>[R]c1ccc2[nH]cc(-c3cc(-c4ccc(Br)s4)no3)c2c1</smiles>

18<smiles>[R]c1ccc2[nH]cc(C3CC(c4ccncc4)=NO3)c2c1</smiles>

16<smiles>[R]c1ccc2[nH]cc(-c3cc(-c4ccncc4)no3)c2c1</smiles>

19
(i) $\mathrm{NH}_{2} \mathrm{OH} . \mathrm{HCl} / \mathrm{EtOH} /$ )))
(ii) Chloranil / Xylene / )))
$\mathbf{R}=$ a) $\mathrm{H}$
b) $\mathrm{F}$

Scheme 3: Synthesis of 3-(aryl)-5-(1H-indol-3-yl)-2-isoxazolines and Isoxazoles.

\begin{tabular}{|c|c|c|c|c|c|c|c|c|}
\hline \multicolumn{9}{|c|}{ Zone of inhibition (mm) } \\
\hline \multirow{3}{*}{ Compound } & \multicolumn{4}{|c|}{ Gram-positive bacteria } & \multicolumn{4}{|c|}{ Gram-negative bacteria } \\
\hline & \multicolumn{2}{|c|}{ S. aureus } & \multicolumn{2}{|c|}{ B. subtilis } & \multicolumn{2}{|c|}{$P$. aeruginosa } & \multicolumn{2}{|c|}{ K. pneumoniae } \\
\hline & $50 \mu \mathrm{g} /$ well & $100 \mu \mathrm{g} / \mathrm{well}$ & $50 \mu \mathrm{g} /$ well & $100 \mu \mathrm{g} / \mathrm{well}$ & $50 \mu g / w e l l$ & $100 \mu \mathrm{g} / \mathrm{well}$ & $50 \mu \mathrm{g} /$ well & $100 \mu \mathrm{g} / \mathrm{wel}$ \\
\hline $8 a$ & - & - & - & - & - & - & - & - \\
\hline $8 b$ & - & $7 \pm 1$ & - & $8 \pm 3$ & - & - & - & $7 \pm 1$ \\
\hline $9 a$ & $11 \pm 2$ & $13 \pm 1$ & $12 \pm 3$ & $14 \pm 3$ & $8 \pm 2$ & $10 \pm 1$ & $11 \pm 2$ & $14 \pm 1$ \\
\hline $9 b$ & $17 \pm 1$ & $19 \pm 3$ & $20 \pm 1$ & $22 \pm 2$ & $16 \pm 3$ & $18 \pm 1$ & $20 \pm 3$ & $21 \pm 1$ \\
\hline $10 a$ & $10 \pm 1$ & $12 \pm 3$ & $11 \pm 2$ & $14 \pm 1$ & $8 \pm 1$ & $11 \pm 3$ & $7 \pm 2$ & $9 \pm 1$ \\
\hline $10 \mathrm{~b}$ & $15 \pm 2$ & $17 \pm 1$ & $16 \pm 3$ & $19 \pm 2$ & $12 \pm 3$ & $15 \pm 1$ & $13 \pm 1$ & $16 \pm 2$ \\
\hline $11 a$ & $13 \pm 1$ & $15 \pm 2$ & $22 \pm 1$ & $25 \pm 3$ & $9 \pm 2$ & $11 \pm 1$ & $16 \pm 3$ & $18 \pm 2$ \\
\hline $11 \mathrm{~b}$ & $23 \pm 3$ & $25 \pm 3$ & $27 \pm 2$ & $30 \pm 2$ & $16 \pm 1$ & $19 \pm 3$ & $25 \pm 2$ & $27 \pm 1$ \\
\hline $12 a$ & $19 \pm 2$ & $21 \pm 1$ & $25 \pm 2$ & $28 \pm 3$ & $15 \pm 3$ & $17 \pm 1$ & $23 \pm 2$ & $25 \pm 3$ \\
\hline $12 b$ & $25 \pm 2$ & $28 \pm 2$ & $35 \pm 1$ & $39 \pm 1$ & $21 \pm 1$ & $24 \pm 3$ & $29 \pm 2$ & $32 \pm 1$ \\
\hline $13 a$ & $17 \pm 3$ & $19 \pm 1$ & $25 \pm 1$ & $28 \pm 1$ & $14 \pm 3$ & $16 \pm 1$ & $21 \pm 2$ & $24 \pm 3$ \\
\hline 13b & $24 \pm 1$ & $27 \pm 3$ & $29 \pm 3$ & $32 \pm 1$ & $19 \pm 1$ & $21 \pm 3$ & $25 \pm 2$ & $28 \pm 1$ \\
\hline $14 a$ & - & - & - & - & - & - & - & - \\
\hline $14 b$ & - & $8 \pm 2$ & - & $10 \pm 1$ & - & - & - & $9 \pm 3$ \\
\hline $15 a$ & $15 \pm 1$ & $17 \pm 2$ & $19 \pm 3$ & $21 \pm 1$ & $14 \pm 3$ & $17 \pm 2$ & $18 \pm 1$ & $20 \pm 3$ \\
\hline $15 b$ & $22 \pm 3$ & $25 \pm 1$ & $27 \pm 2$ & $28 \pm 1$ & $20 \pm 1$ & $23 \pm 3$ & $24 \pm 1$ & $26 \pm 2$ \\
\hline $16 a$ & $13 \pm 1$ & $15 \pm 2$ & $17 \pm 2$ & $19 \pm 1$ & $13 \pm 2$ & $15 \pm 2$ & $16 \pm 1$ & $19 \pm 3$ \\
\hline $16 b$ & $19 \pm 3$ & $21 \pm 3$ & $25 \pm 3$ & $27 \pm 3$ & $17 \pm 1$ & $19 \pm 3$ & $22 \pm 3$ & $25 \pm 2$ \\
\hline $17 a$ & $16 \pm 3$ & $18 \pm 1$ & $23 \pm 1$ & $27 \pm 3$ & $11 \pm 2$ & $13 \pm 1$ & $18 \pm 3$ & $20 \pm 2$ \\
\hline $17 b$ & $27 \pm 2$ & $29 \pm 1$ & $29 \pm 3$ & $32 \pm 1$ & $19 \pm 3$ & $22 \pm 2$ & $29 \pm 1$ & $33 \pm 3$ \\
\hline $18 a$ & $22 \pm 1$ & $25 \pm 1$ & $28 \pm 3$ & $30 \pm 2$ & $17 \pm 2$ & $19 \pm 1$ & $24 \pm 3$ & $27 \pm 2$ \\
\hline $18 b$ & $28 \pm 3$ & $31 \pm 3$ & $37 \pm 1$ & $41 \pm 1$ & $23 \pm 1$ & $26 \pm 2$ & $32 \pm 3$ & $35 \pm 1$ \\
\hline $19 a$ & $18 \pm 3$ & $20 \pm 1$ & $26 \pm 2$ & $29 \pm 3$ & $12 \pm 2$ & $15 \pm 3$ & $26 \pm 1$ & $29 \pm 2$ \\
\hline $19 b$ & $25 \pm 2$ & $31 \pm 1$ & $32 \pm 1$ & $34 \pm 2$ & $20 \pm 3$ & $23 \pm 2$ & $27 \pm 1$ & $30 \pm 3$ \\
\hline Chloramphenicol & $33 \pm 1$ & $35 \pm 3$ & $34 \pm 2$ & $38 \pm 3$ & $27 \pm 1$ & $30 \pm 3$ & $40 \pm 2$ & $42 \pm 1$ \\
\hline Control (DMSO) & - & - & - & - & - & - & - & - \\
\hline
\end{tabular}


Citation: Reddy SP, Yamini G, Sowmya DV, Padmavathi V, Padmaja A (2017) Synthesis and Antimicrobial Activity of Some New 3,5-Disubstituted Pyrazoles and Isoxazoles. Med Chem (Los Angeles) 7: 371-380. doi: 10.4172/2161-0444.10483

\begin{tabular}{|c|c|c|c|c|}
\hline \multicolumn{5}{|c|}{ Zone of inhibition (mm) } \\
\hline \multirow{2}{*}{ Compound } & \multicolumn{2}{|c|}{ A. niger } & \multicolumn{2}{|c|}{ P. chrysogenum } \\
\hline & $50 \mu \mathrm{g} /$ well & $100 \mu \mathrm{g} /$ well & $50 \mu \mathrm{g} /$ well & $100 \mu \mathrm{g} /$ well \\
\hline $8 a$ & - & - & - & - \\
\hline $8 b$ & $9 \pm 3$ & $11 \pm 3$ & - & $8 \pm 2$ \\
\hline $9 a$ & $13 \pm 2$ & $15 \pm 1$ & $8 \pm 1$ & $10 \pm 3$ \\
\hline $9 b$ & $20 \pm 3$ & $22 \pm 2$ & $17 \pm 1$ & $19 \pm 2$ \\
\hline $10 a$ & $12 \pm 3$ & $14 \pm 2$ & $7 \pm 1$ & $9 \pm 2$ \\
\hline $10 \mathrm{~b}$ & $16 \pm 1$ & $19 \pm 3$ & $14 \pm 2$ & $16 \pm 2$ \\
\hline $11 a$ & $14 \pm 2$ & $17 \pm 3$ & $10 \pm 1$ & $12 \pm 3$ \\
\hline 11b & $25 \pm 1$ & $28 \pm 1$ & $18 \pm 2$ & $21 \pm 3$ \\
\hline $12 a$ & $24 \pm 1$ & $26 \pm 2$ & $15 \pm 3$ & $17 \pm 2$ \\
\hline $12 b$ & $34 \pm 3$ & $37 \pm 2$ & $26 \pm 1$ & $29 \pm 3$ \\
\hline $13 a$ & $19 \pm 1$ & $21 \pm 2$ & $12 \pm 1$ & $14 \pm 3$ \\
\hline $13 b$ & $28 \pm 3$ & $31 \pm 1$ & $19 \pm 2$ & $23 \pm 1$ \\
\hline $14 a$ & - & - & - & - \\
\hline $14 b$ & $11 \pm 1$ & $13 \pm 2$ & $8 \pm 2$ & $10 \pm 3$ \\
\hline $15 a$ & $18 \pm 2$ & $21 \pm 1$ & $13 \pm 1$ & $15 \pm 3$ \\
\hline $15 b$ & $28 \pm 1$ & $30 \pm 2$ & $22 \pm 3$ & $24 \pm 3$ \\
\hline $16 a$ & $14 \pm 2$ & $18 \pm 3$ & $10 \pm 3$ & $13 \pm 2$ \\
\hline $16 b$ & $23 \pm 1$ & $26 \pm 1$ & $20 \pm 2$ & $22 \pm 3$ \\
\hline $17 a$ & $15 \pm 1$ & $18 \pm 1$ & $11 \pm 3$ & $14 \pm 1$ \\
\hline $17 b$ & $27 \pm 3$ & $30 \pm 2$ & $23 \pm 1$ & $26 \pm 1$ \\
\hline $18 a$ & $29 \pm 3$ & $32 \pm 2$ & $16 \pm 1$ & $19 \pm 2$ \\
\hline $18 b$ & $35 \pm 2$ & $39 \pm 3$ & $28 \pm 1$ & $31 \pm 1$ \\
\hline $19 a$ & $23 \pm 2$ & $25 \pm 3$ & $13 \pm 2$ & $15 \pm 1$ \\
\hline $19 b$ & $32 \pm 1$ & $34 \pm 2$ & $25 \pm 3$ & $27 \pm 2$ \\
\hline Ketoconazole & $33 \pm 2$ & $36 \pm 3$ & $35 \pm 1$ & $38 \pm 3$ \\
\hline Control (DMSO) & - & - & - & - \\
\hline
\end{tabular}

- No activity; \pm Standard deviation

Table 2 The in vitro antifungal activity of compounds 8-19.

\begin{tabular}{|c|c|c|c|c|c|c|}
\hline \multirow{2}{*}{ Compound } & \multicolumn{6}{|c|}{ Minimum inhibitory concentration MIC (MBC/MFC) $\mu \mathrm{g} /$ well } \\
\hline & S. aureus & B. subtilis & P. aeruginosa & K. pneumoniae & A. niger & P. chrysogenum \\
\hline $12 b$ & $50(200)$ & $6.25(12.5)$ & $50(>200)$ & $100(>200)$ & $12.5(25)$ & $25(100)$ \\
\hline $18 b$ & $25(100)$ & $6.25(12.5)$ & $50(200)$ & $100(>200)$ & $12.5(25)$ & $25(100)$ \\
\hline Chloramphenicol & 12.5 & 6.25 & 6.25 & 6.25 & - & - \\
\hline Ketoconazole & - & - & - & - & 6.25 & 12.5 \\
\hline
\end{tabular}

- No activity; \pm Standard deviation

Table 3: MIC, MBC and MFC of compounds $12 \mathrm{~b}$ and $18 \mathrm{~b}$

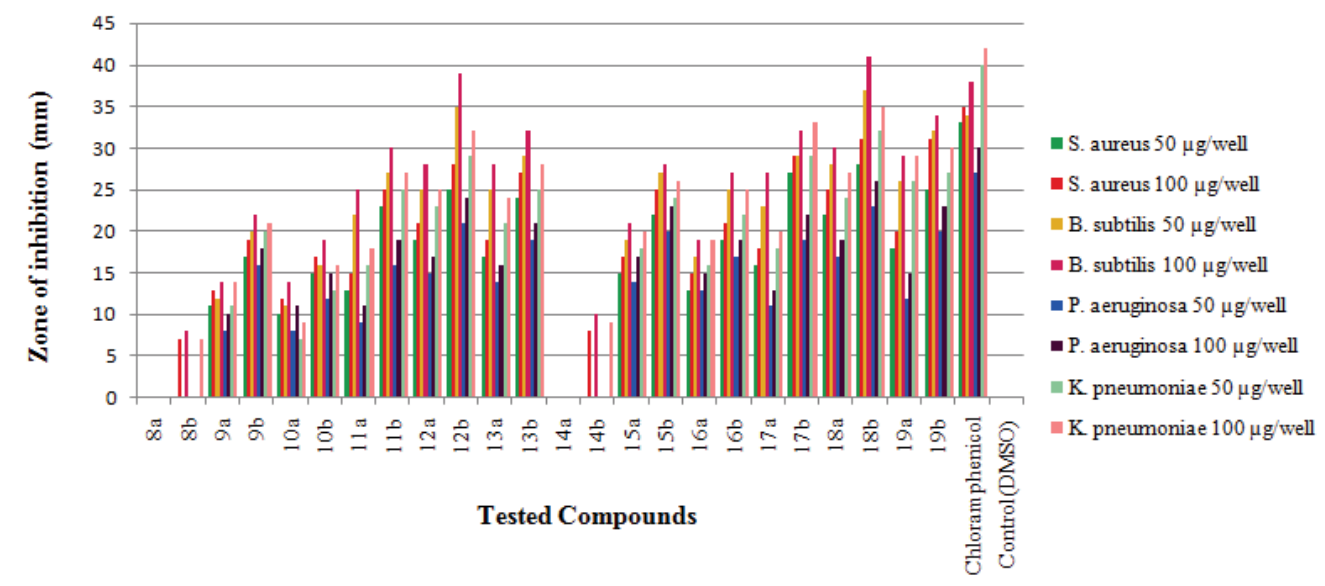

Figure 1: The in vitro antibacterial activity of compounds 8-19. 


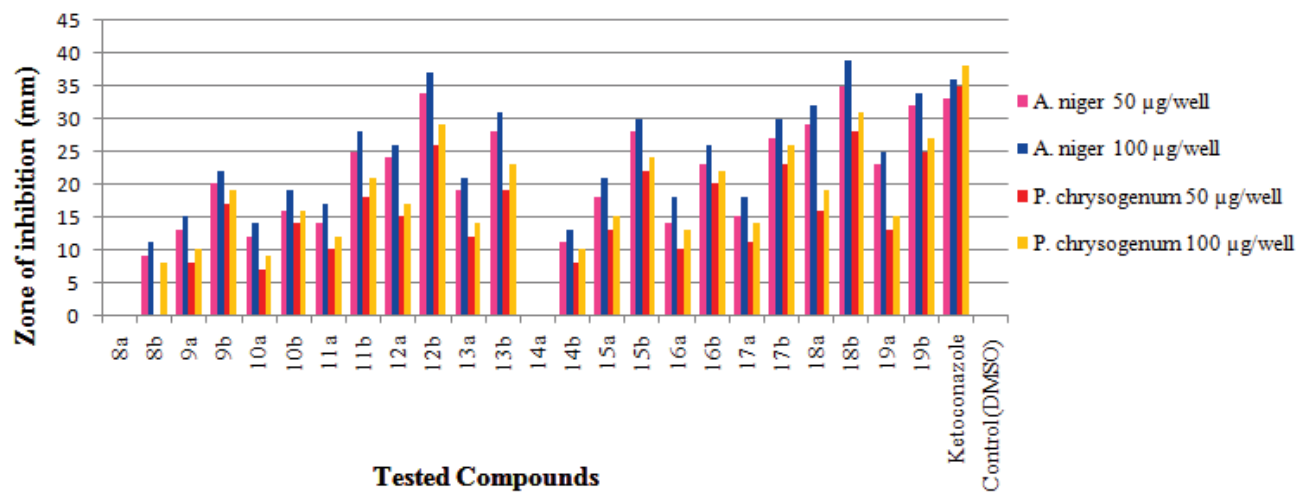

Figure 2: The in vitro antifungal activity of compounds 8-19.

activity than non-aromatized compounds 8-10 and 14-16. Moreover aromatized heterocyclic compounds having isoxazole unit displayed slightly higher activity than pyrazole unit. This is may be due to the presence of electron withdrawing oxygen atom. It was also noticed that compounds having electron withdrawing fluoro substituent on aromatic ring enhanced the activity when compared with the unsubstituted ones. Besides, the compounds having more number of electron withdrawing groups showed increased antimicrobial activity. Amongst all the compounds $\mathbf{1 2 b}$ and $\mathbf{1 8 b}$ were found to be potential antimicrobial agents particularly against Bacillus subtilis and Aspergillus niger. This result indicates that compounds $\mathbf{1 2 b}$ and $\mathbf{1 8 b}$ can be used as lead compounds in the future studies.

\section{Conclusion}

A new class of 3,5-disubstituted pyrazoles and isoxazoles were prepared from the Michael acceptors 1-furanyl / thiophenyl / pyridinyl3-indole-prop-2-en-1-ones under ultrasonication and evaluated for antimicrobial activity. In fact, the target compounds were obtained in shorter reaction times with high yield under ultrasonication when compared with conventional method. Amongst all the tested compounds $12 \mathrm{~b}$ and $18 \mathrm{~b}$ displayed promising antimicrobial activity particularly against Bacillus subtilis and Aspergillus niger. The presence of electron withdrawing fluoro substituent on the aromatic ring enhanced the activity than the unsubstituted ones. Furthermore, compounds with more number of electron withdrawing groups showed higher antimicrobial activity. This result indicates that compounds $12 \mathrm{~b}$ and $18 \mathrm{~b}$ can be used as lead compounds in the future studies.

\section{Acknowledgments}

One of the authors, G. Yamini is thankful to University Grants Commission (UGC), New Delhi for the sanction of UGC-BSR fellowship. The authors are also thankful to Prof. P. Uma Maheswari Devi, Department of applied microbiology, Sri Padmavathi Mahila Visvavidyalayam, Tirupati for providing necessary facilities to carry out the antimicrobial activity.

\section{References}

1. Ragavan RV, Vijayakumar V, Kumari NS (2010) Synthesis and antimicrobial activities of novel 1,5-diaryl pyrazoles. European Journal of Medicinal Chemistry 45: 1173-1180.

2. Vijesh A, Isloor AM, Shetty P, Sundershan S, Fun HK (2013) New pyrazole derivatives containing 1,2,4-triazoles and benzoxazoles as potent antimicrobial and analgesic agents. European Journal of Medicinal Chemistry 62: 410-415.

3. Wael A, Sayed E, Nassar IF, Adel AH, Rahman A (2009) C-Furyl glycosides, II: synthesis and antimicrobial evaluation of $C$-furyl glycosides bearing pyrazolines, isoxazolines, and 5,6-dihydropyrimidine-2(1H)-thiones. Monatshefte fur Chemie 140: 365-370.
4. Jadhav SB, Shastri RA, Gaikwad KV, Gaikwad SV (2009) Synthesis and antimicrobial studies of some novel pyrazoline and isoxazoline derivatives. European Journal of Medicinal Chemistry 6: S183-S188.

5. Korgaokar SS, Patil PH, Shab MT, Parekh HH (1996) Studies on pyrazolines: preparation and antimicrobial activity of 3-(3'(PChlorophenylsulphonamidophenyl)-5-aryl-1H/Acetyl pyrazolines. Indian Journal of Pharmaceutical Sciences 58: 222-225.

6. Nauduri D, Reddy GB (1998) Anti bacterials and antimycotics: Part 1: Synthesis and activity of 2-pyrazoline derivatives. Chemical and Pharmaceutical Bulletin 46: $1254-1260$.

7. Gokhan-Kelekci N, Yabanoglu S, Kupeli E, Salgin U, Ozgen O, et al. (2007) A new therapeutic approach in alzheimer disease: Some novel pyrazole derivatives as dual MAO-B inhibitors and anti-inflammatory analgesics. Bioorganic and Medicinal Chemistry 15: 5775-5786.

8. Shivkumar B, Nargund LVG (1998) Synthesis of substituted fluoro isoxazoles, isoxazolines and pyridones as anti-inflammatory agents. Indian Journal of Heterocyclic Chemistry 8: 27-30.

9. Balbi A, Anzaldi M, Macciò C, Aiello C, Mazzei M, et al. (2011) Synthesis and biological evaluation of novel pyrazole derivatives with anticancer activity. European Journal of Medicinal Chemistry 46: 5293-5309.

10. Sadanandam A, Rajam MV, Subhash K, Rajanarendar E (1984) Production of chromosomal breaks by isoxazolyl thiazolidinone in allium sativa. Indian Bot Rep 3: 38-42.

11. Hall A, Billinton A, Brown SH, Clayton NM, Chowdhury A, et al. (2008) Nonacidic pyrazole EP1 receptor antagonists with in vivo analgesic efficacy. Bioorganic and Medicinal Chemistry Letters 18: 3392-3399.

12. Kano H, Adachi I, Kido R, Hirose K (1967) Isoxazoles. XVIII. Synthesis and pharmacological properties of 5-aminoalkyl- and 3-aminoalkylisoxazoles and related derivatives. Journal of Medicinal Chemistry 10: 411-418.

13. Kaushik D, Khan SA, Chawla G, Kumar S (2010) N'-[(5-chloro-3-methyl-1phenyl-1H-pyrazol-4-yl)methylene] 2/4-substituted hydrazides: Synthesis and anticonvulsant activity. European Journal of Medicinal Chemistry 45: 39433949.

14. Uno H, Kurokawa M, Masuda $Y$, Nishimuura $H$ (1979) Studies on 3-substituted 1,2-benzisoxazole derivatives. 6. synthesis of 3-(sulfamoylmethyl)-1,2 benzisoxazol derivatives and their anticonvulsant activities Journal of Medicinal Chemistry 22: 180-183.

15. Getal G (1975) The isolation, structure, and absolute configuration of u-43.795, a new antitumor agent. Journal of Antibiotics 28: 91-93.

16. Padmaja A, Payani T, Dinneswara Reddy G, Padmavathi V (2009) Synthesis, antimicrobial and antioxidant activities of substituted pyrazoles, isoxazoles, pyrimidine and thioxopyrimidine derivatives. European Journal of Medicinal Chemistry 44: 4557-4566.

17. Penning TD, Talley JJ, Bertenshaw SR, Carter JS, Collins PW, et al. (1997) Synthesis and biological evaluation of the 1,5-diarylpyrazole class of cyclooxygenase-2 inhibitors: identification of 4-[5-(4-Methylphenyl)-3(trifluoromethyl)-1H-pyrazol-1-yl]benzenesulfonamide (SC-58635, Celecoxib). Journal of Medicinal Chemistry 40: 1347-1365 
Citation: Reddy SP, Yamini G, Sowmya DV, Padmavathi V, Padmaja A (2017) Synthesis and Antimicrobial Activity of Some New 3,5-Disubstituted Pyrazoles and Isoxazoles. Med Chem (Los Angeles) 7: 371-380. doi: 10.4172/2161-0444.10483

18. Katoch-Rouse R, Pavlova OA, Caulder V, Hoffman AF, Mukhin AG, et al. (2003) Synthesis, structure-activity relationship, and evaluation of SR141716 analogues: development of central cannabinoid receptor ligands with lower lipophilicity. Journal of Medicinal Chemistry 46: 642-645.

19. Terrett NK, Bell AS, Brown D, Ellis $P$ (1996) Sildenafil (viagra), a potent and selective inhibitor of type $5 \mathrm{cgmp}$ phosphodiesterase with utility for the treatment of male erectile disfunction. Bioorganic and Medicinal Chemistry Letters 6: 1819-1824.

20. Kobinata K, Sekido S, Uramoto M, Ubukato M, Osada H, et al. (1991) Isoxazole4-carboxylic acid as a metabolite of streptomyces sp. and its herbicidal activity. Agricultural and Biological Chemistry 55: 1415-1416.

21. Rozman B, Praprotnik S, Logar D, Tomsic M, Hijnik M, et al. (2002) Leflunomide and hypertension. Annals of the Rheumatic Diseases 61: 567-569.

22. Lawrence SL, Roth V, Slinger R, Toye B, Gaboury I, et al. (2005) Cloxacillin versus vancomycin for presumed late-onset sepsis in the neonatal intensive care unit and the impact upon outcome of coagulase negative staphylococcal bacteremia: a retrospective cohort study. BMC Pediatrics 5: 49-56.

23. Shin KD, Lee MY, Shin DS, Lee S, Son KH, et al. (2005) Blocking tumor cell migration and invasion with biphenyl isoxazole derivative KHIBB3, a synthetic molecule that inhibits Hsp27 phosphorylation. Journal of Biological Chemistry 50: 41439-41448.

24. Lee YS, Park SM, Kim BH (2009) Synthesis of 5-isoxazol-5-yl-20-deoxyuridines exhibiting antiviral activity against HSV and several RNA viruses. Bioorganic and Medicinal Chemistry Letters 19: 1126-1128.

25. Sutherland R, Croydon EAP, Rolinson N (1970) Flucloxacillin, a new isoxazoly penicillin, compared with oxacillin, cloxacillin, and dicloxacillin. British Medical Journal 4: 455-460.

26. Fagervall I, Ross SB (1986) Inhibition of mono amine oxidase in monoaminergic neurons in the rat brain by irreversible inhibitors. Biochemical Pharmacology 35: $1381-1387$.

27. Kochetkov NK, Sokolov SD (1963) Recent developments in isoxazole chemistry. Advances in Heterocyclic Chemistry 2: 365-422.

28. Svete $J$ (2006) Utilisation of chiral enaminones and azomethine imines in the synthesis of functionalised pyrazoles. Arkivoc 7: 35-56.
29. Pinhoemelo TMVD (2005) Recent advances on the synthesis and reactivity of isoxazoles. Current Organic Chemistry 9: 925-958.

30. Sravya G, Yamini G, Padmavathi V, Padmaja A (2016) Synthesis and antimicrobial activity of styryl/pyrrolyl/pyrazolylsulfonylmethyl-1,3,4-oxadiazolyl amines and styryl/pyrrolyl/pyrazolyl sulfonylmethyl-1,3,4-thiadiazolyl amines. European Journal of Medicinal Chemistry 122: 647-655.

31. Muralikrishna A, Mallikarjuna Reddy G, Lavanya G, Padmavathi V, Padmaja A (2014) Synthesis of new class of sulfonamide bis heterocycles-Pyrrolyl/ pyrazolyl-1,3,4-oxadiazoles, 1,3,4-thiadiazoles and 1,2,4-triazoles. Journal of Heterocyclic chemistry 51: 179-190.

32. Padmaja A, Rajasekhar C, Durgamma S, Venkatesh BC, Padmavathi V (2014) Synthesis and antioxidant activity of pyrazolyl oxazolines/thiazolines and isoxazolyl-oxazolines / thiazolines. Medicinal Chemistry Research 23: 1084-1098.

33. Mallikarjuna Reddy G, Ramachandra Reddy P, Padmavathi V, Padmaja A (2013) Synthesis and antioxidant activity of a new class of mono and bisheterocycles. Archiv der Pharmazie 346: 154-162.

34. Cintas P, Palmisano G, Cravotto G (2011) Power ultrasound in metal-assisted synthesis: From classical Barbier-like reactions to click chemistry. Ultrasonics Sonochemistry 18: 836-841.

35. Chung KT, Thomasson WR, Wu-Yuan CD (1990) Growth inhibition of selected food-bornebacteria, particularly Listeria monocytogenes by plant extracts. Journal of Applied Bacteriology 69: 498-503.

36. Azoro C (2002) Antibacterial activity of crude aqueous extracts of Azadirachta indica on Salmonella typhi. World Journal of Biotechnology 3: 347-357.

37. Janovska D, Kubikova K, Kokoska L (2003) Screening for antimicrobial activity of some medicinal plants species of traditional chinese medicine. Czech Journal of Food Science 21: 107-110.

38. Bishnu J, Sunil L, Anuja S (2009) Antibacterial property of different medicinal plants: ocimum sanctum, cinnamomum zeylanicum, xanthoxylum armatum and origanum majorana. Journal of Science Engineering and Technology 5: 143-150.

39. Clinical and Laboratory Standards Institute (CLSI) (2006) Methods for dilution antimicrobial susceptibility tests for bacteria that grow aerobically approved standard-seventh edition. CLSI document M7-A7, Wayne, Pennsylvania, USA.

40. Clinical and Laboratory Standards Institute (CLSI) (2008) Reference method for broth dilution antifungal susceptibility testing of yeasts, approved standardsecond edition. NCCLS document M27-A2, Wayne, Pennsylvania, USA 